\title{
Co-Existence Ecology of Large Predators in Belize
}

Brogan Holcombe, Chris Rowe, Dr. Marcella Kelly Virginia Tech

The National Conferences of Undergraduate Research 2018

April 5, 2018

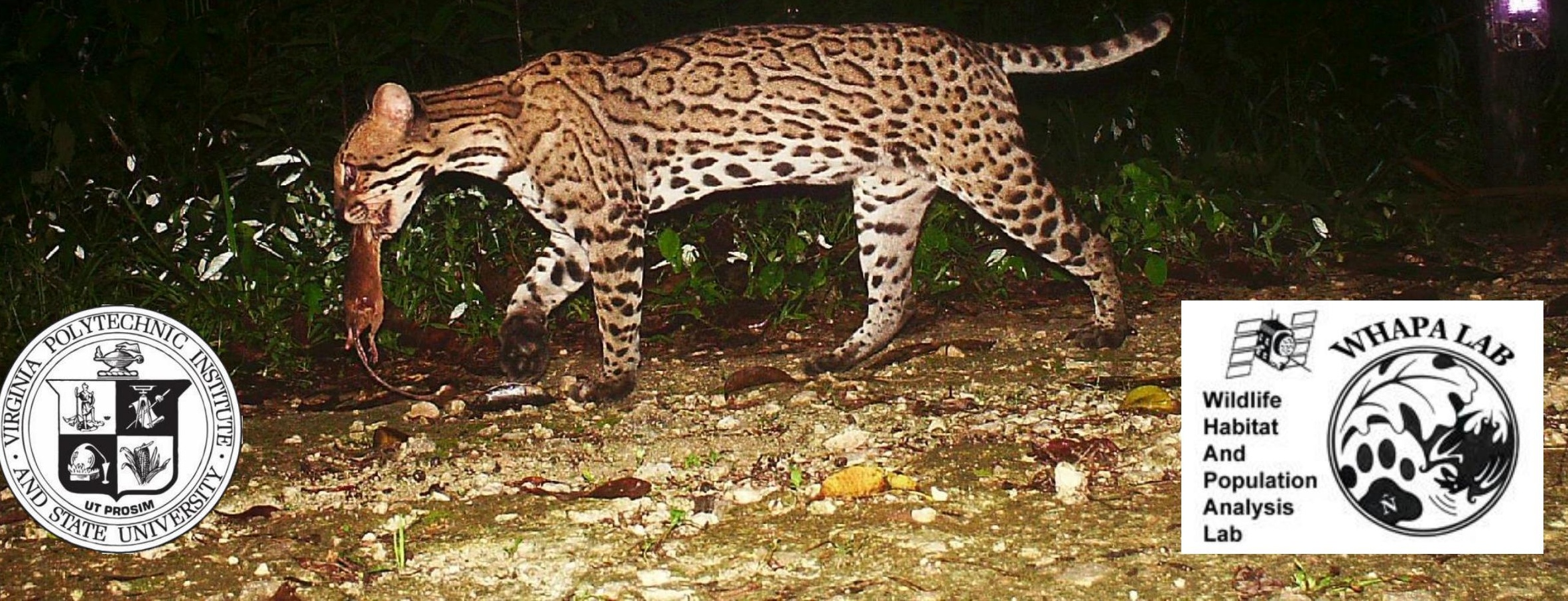




\section{The Jaguar Project}

* Camera Stations

- 2 remotely triggered trail camera along various trails

- Taking pictures of elusive species in dense jungle terrain

$\because$ Regularly spaced stations across landscape

Keeping track of them in Belize, Central America for conservation efforts

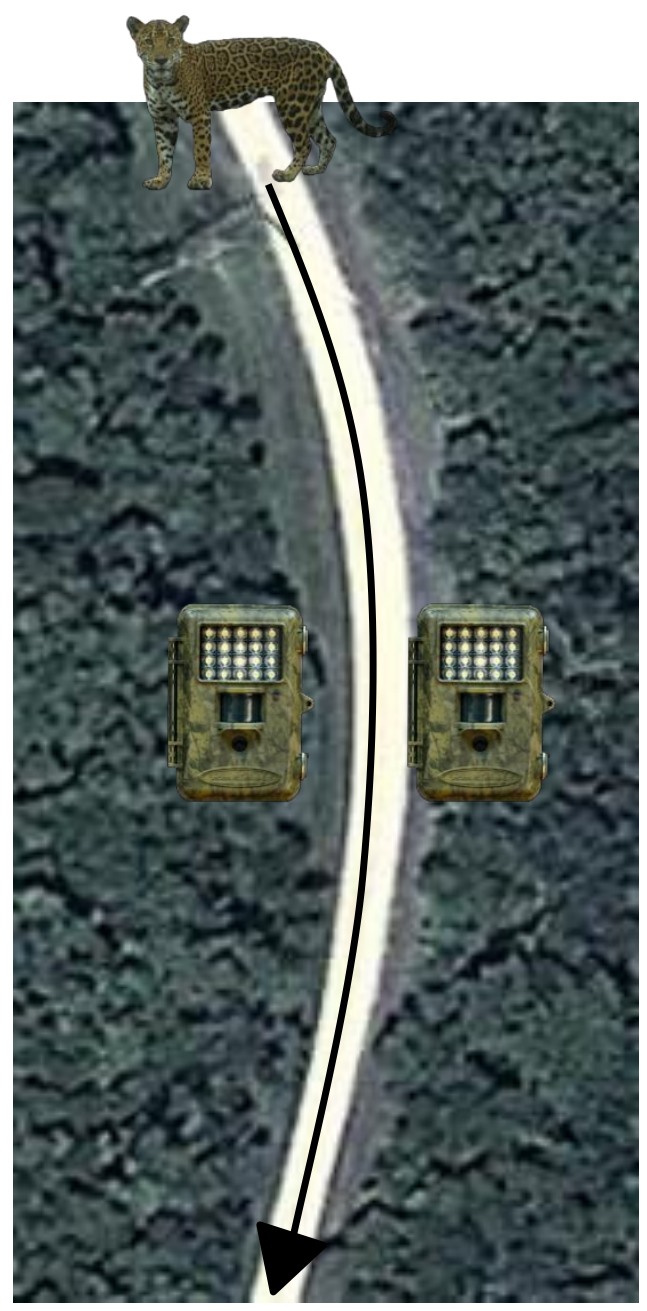




\section{Study Sites}

$\because$ Belize, Central America

$\approx 112$ camera stations

$\because 6,451$ trap nights

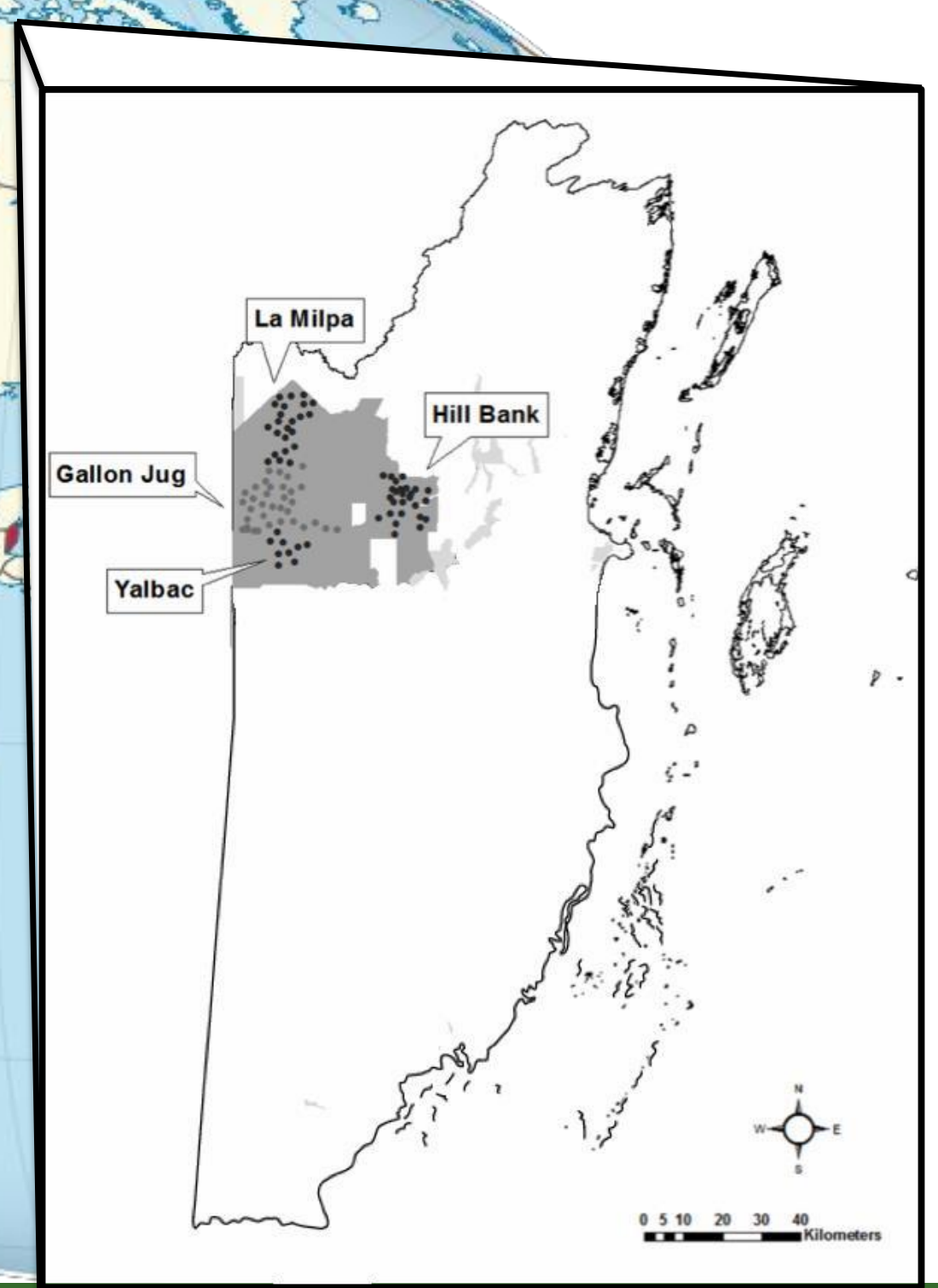




\section{My work with the Jaguar Project}

$\because$ Started out just doing basic photo data entry

$\because$ Became interested in co-existence ecology

$\because$ Received a grant for the field project for the summer 2017 survey

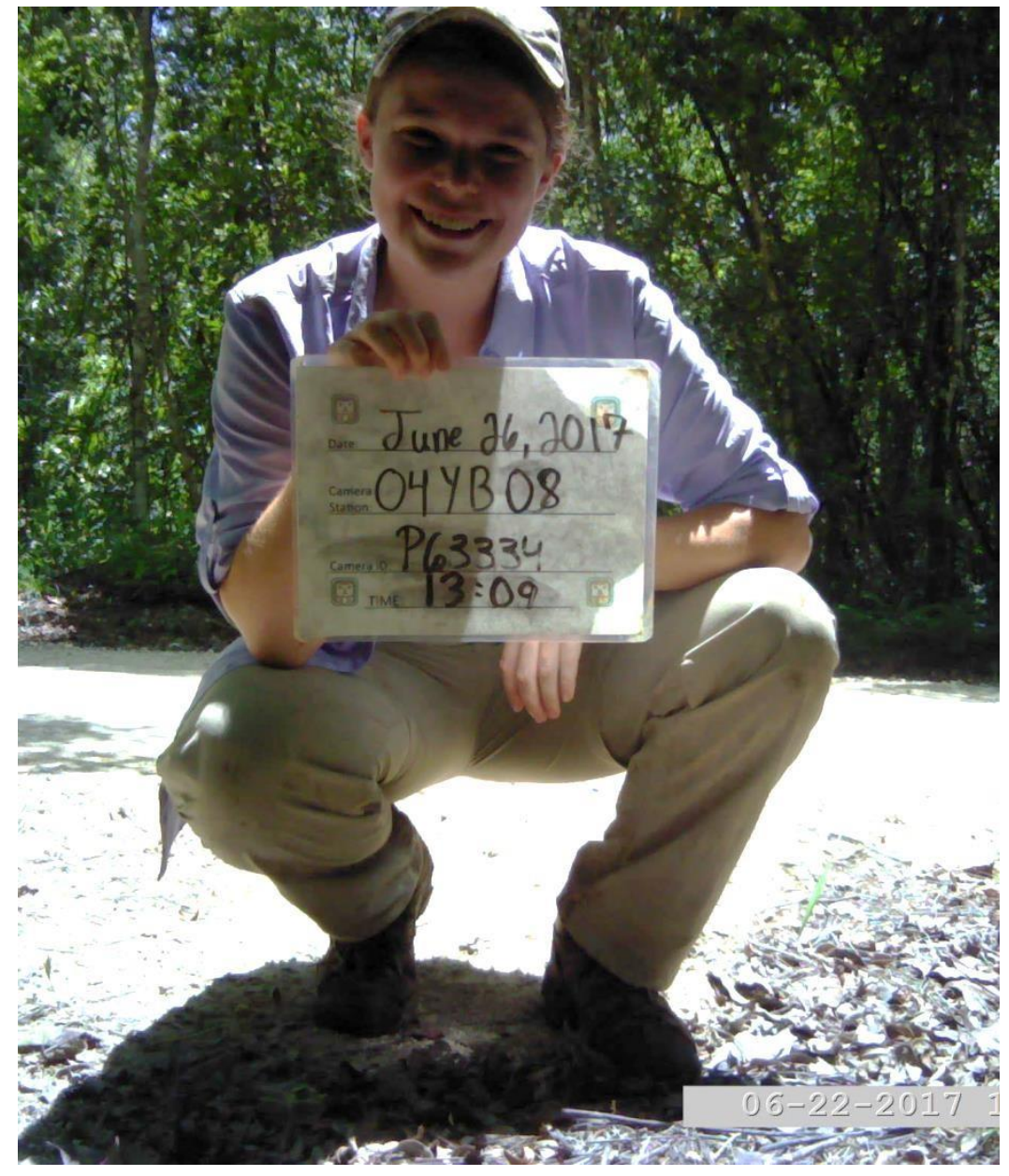




\section{Co-Existence Ecology}

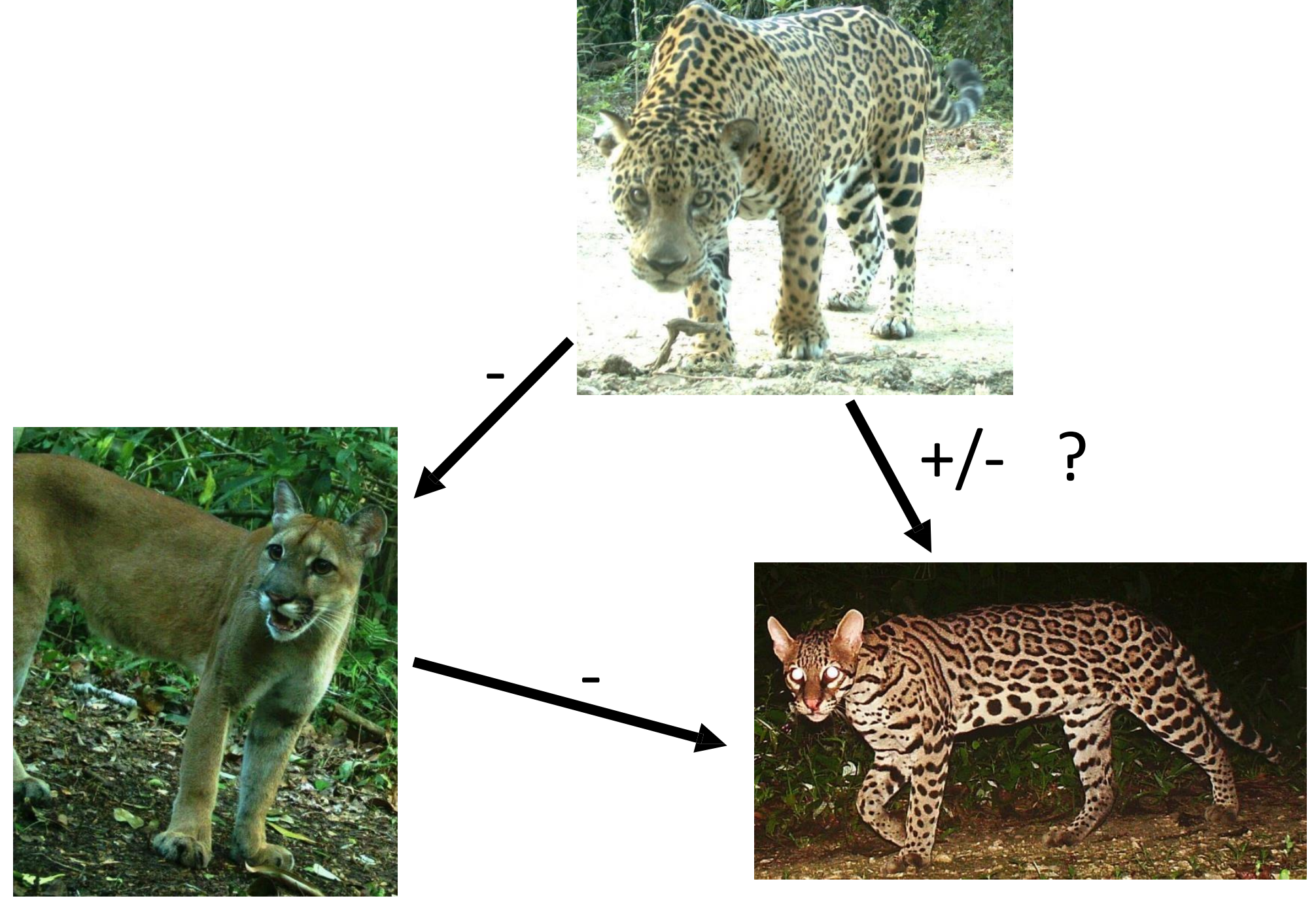




\section{Conservation Issues}

:Conservation efforts working to protect one species may impact other species

* Improving management efforts practices

$\because$ Different land uses effect species differently

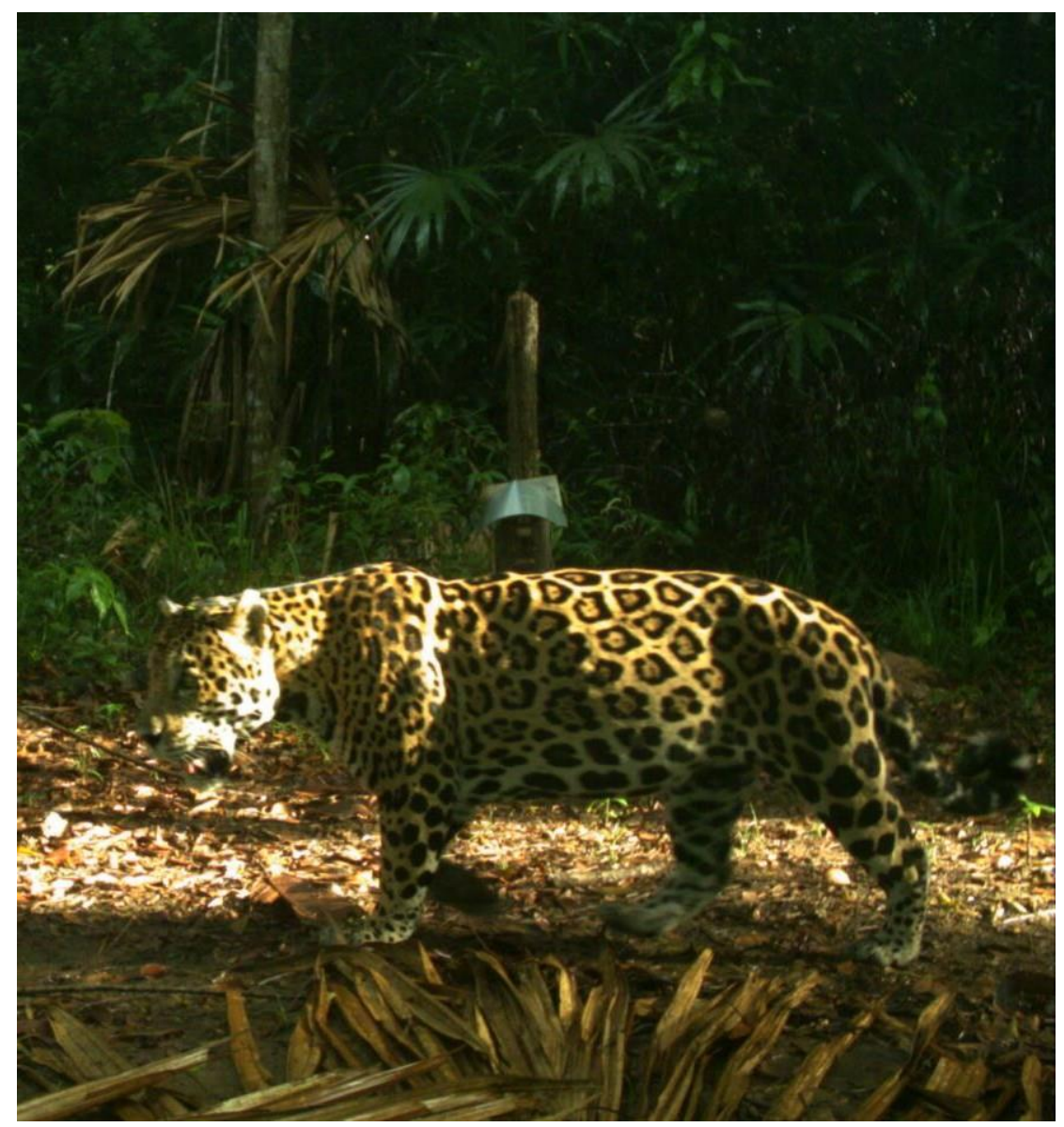




\section{Co-Existence Ecology Between Sexes}

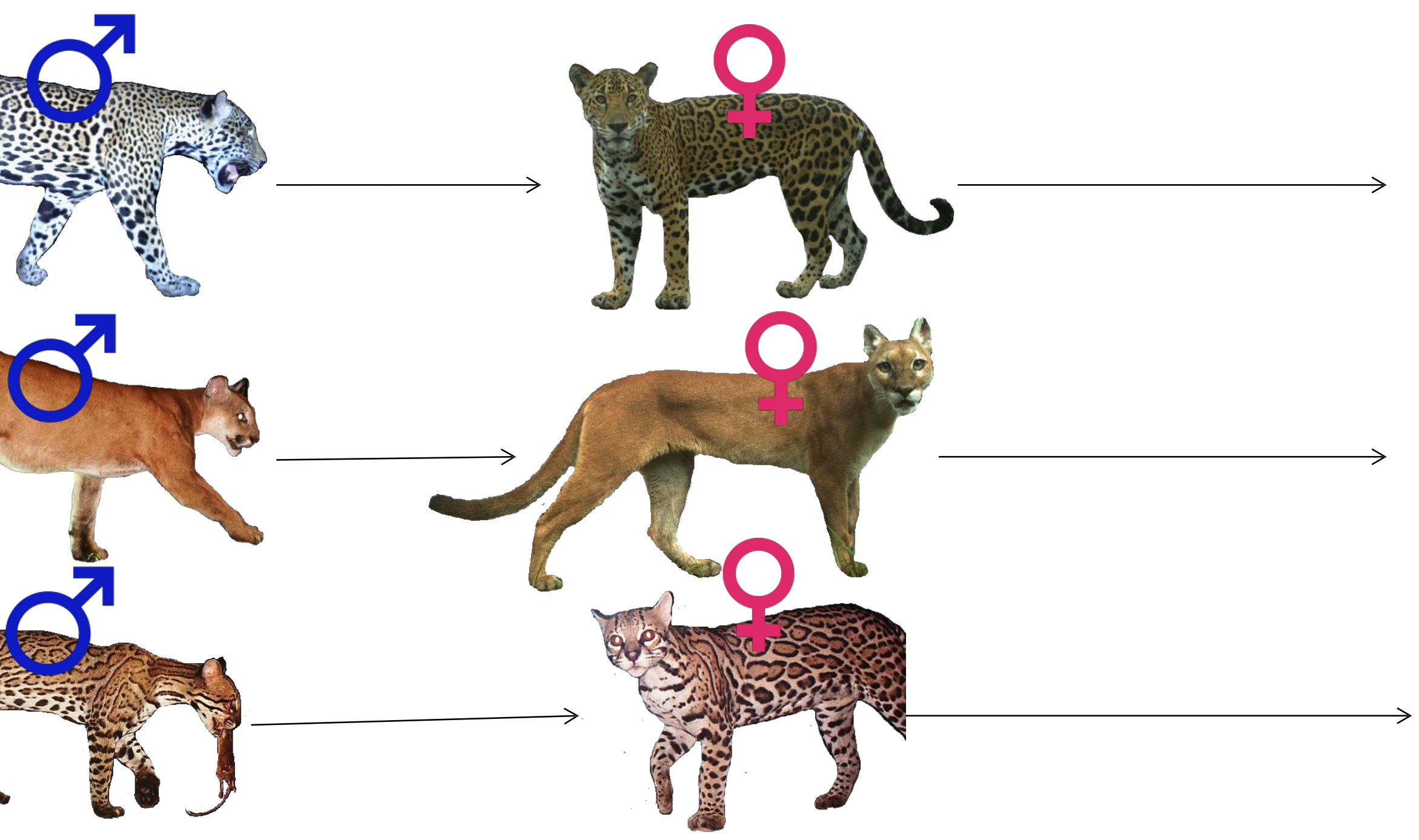




\section{Occupancy \& Detection Modeling}

* Occupancy

- distribution across the landscape

$\because$ Detection

- determining how many times they're detected by the cameras

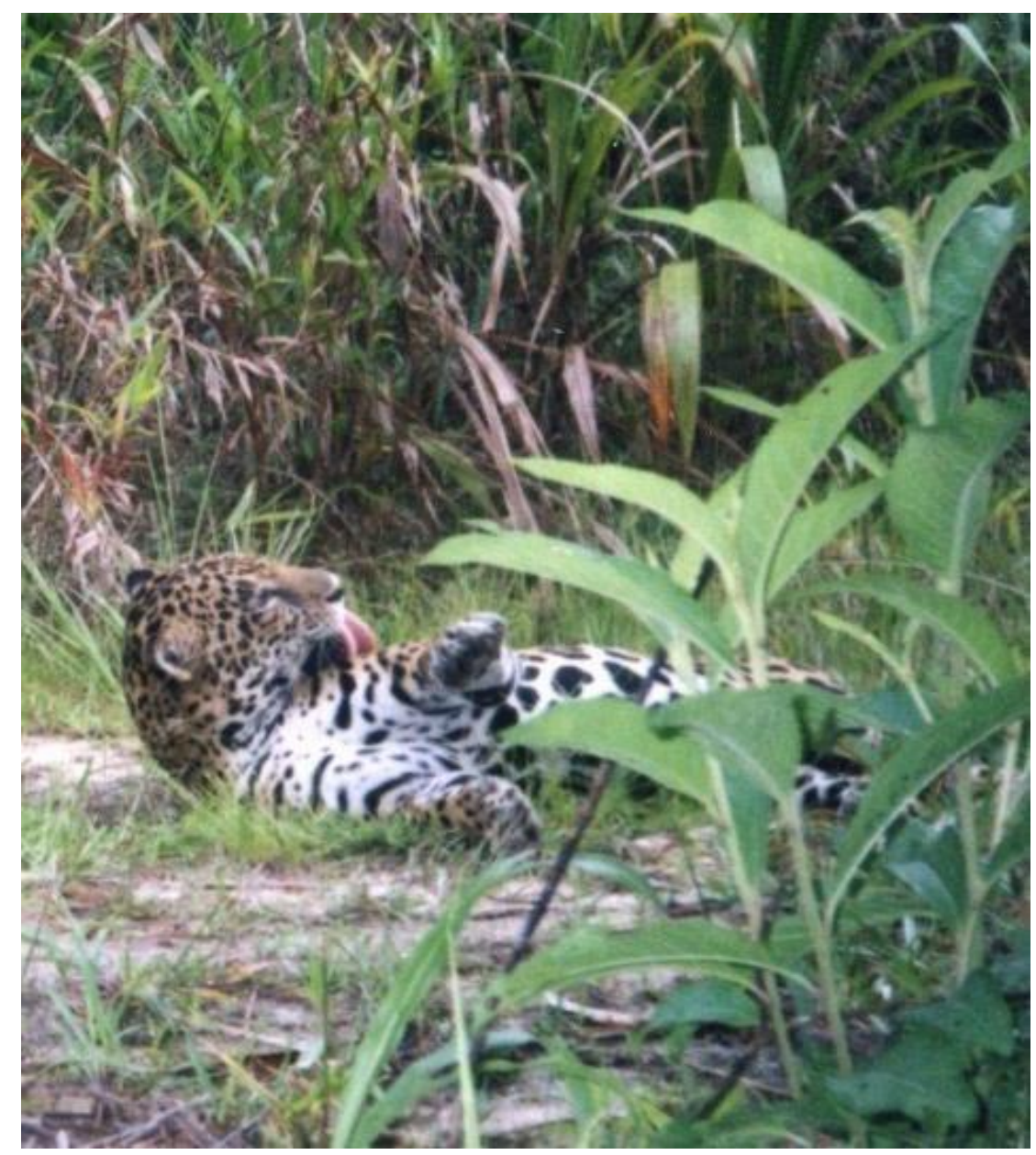




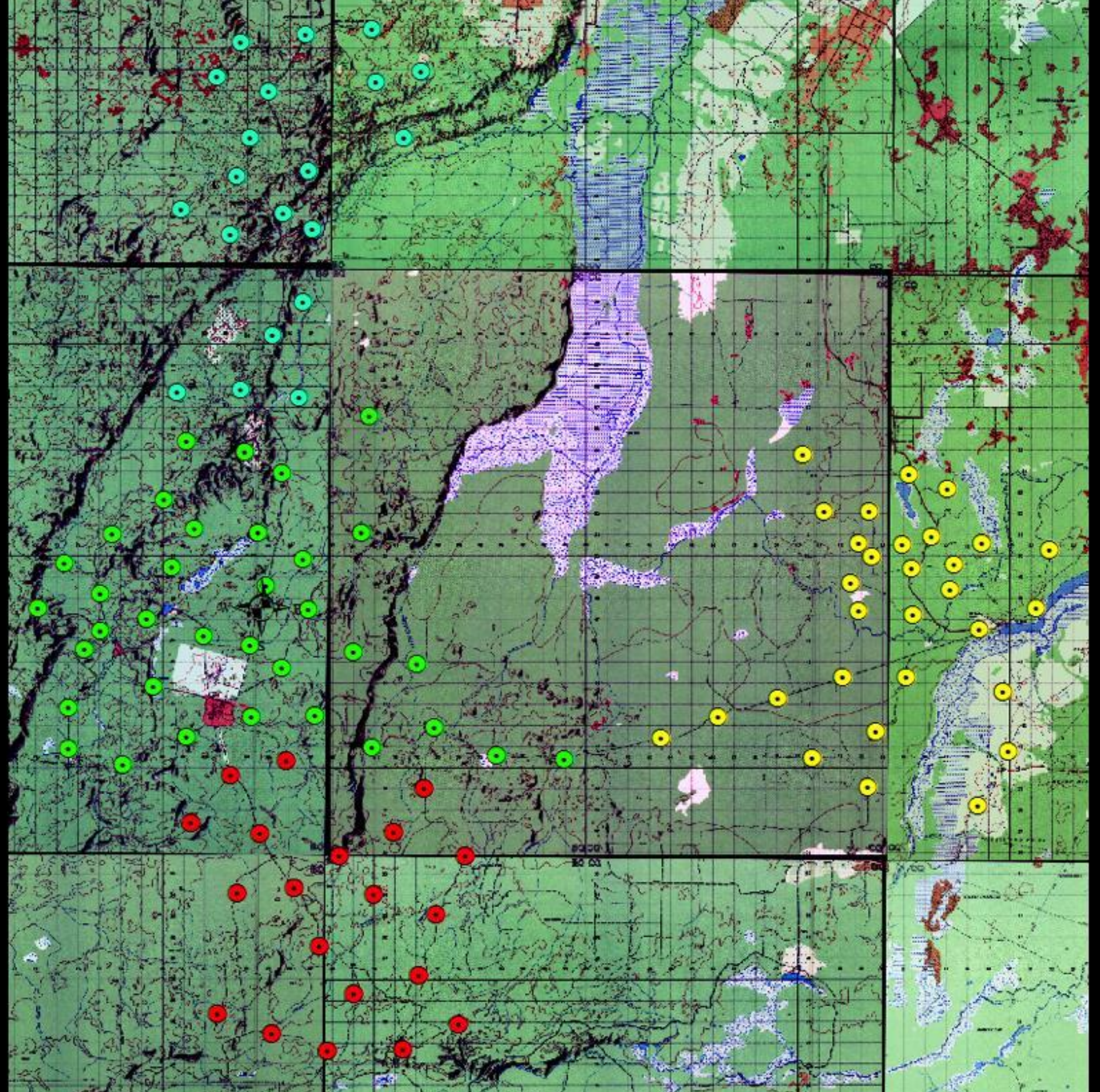




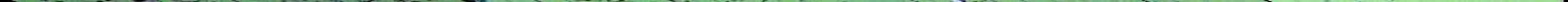




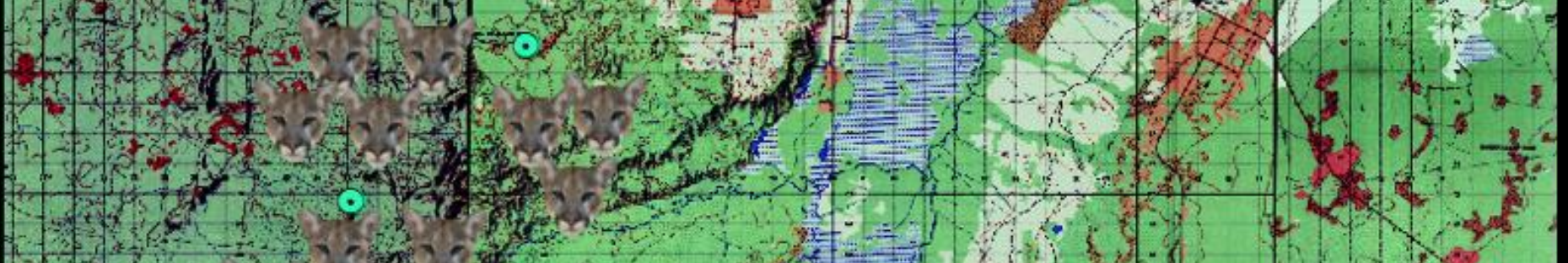

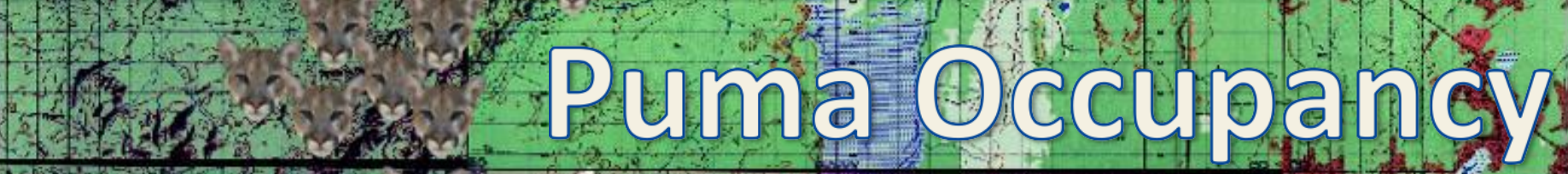
r.t. $83.9 \%$

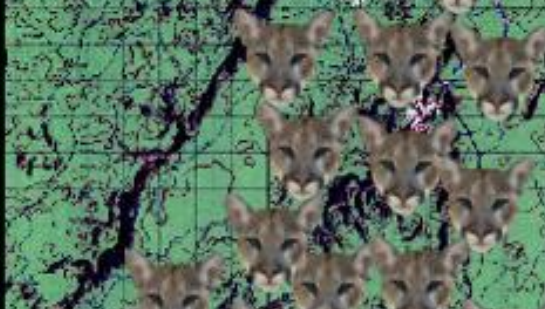

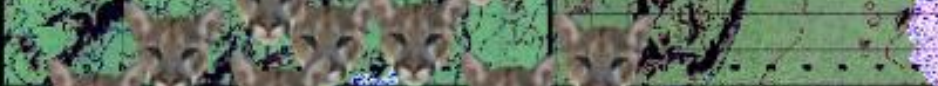

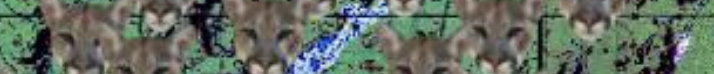

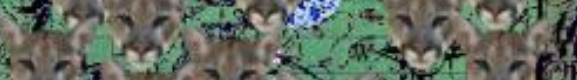

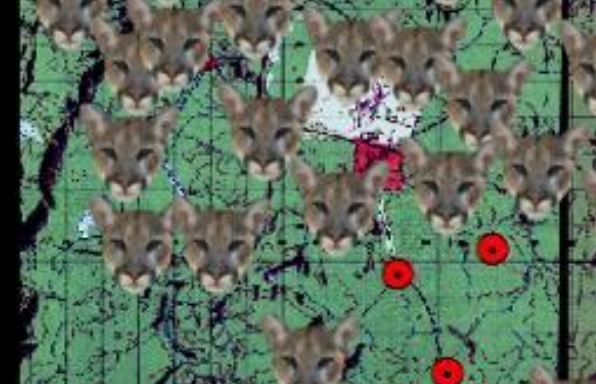

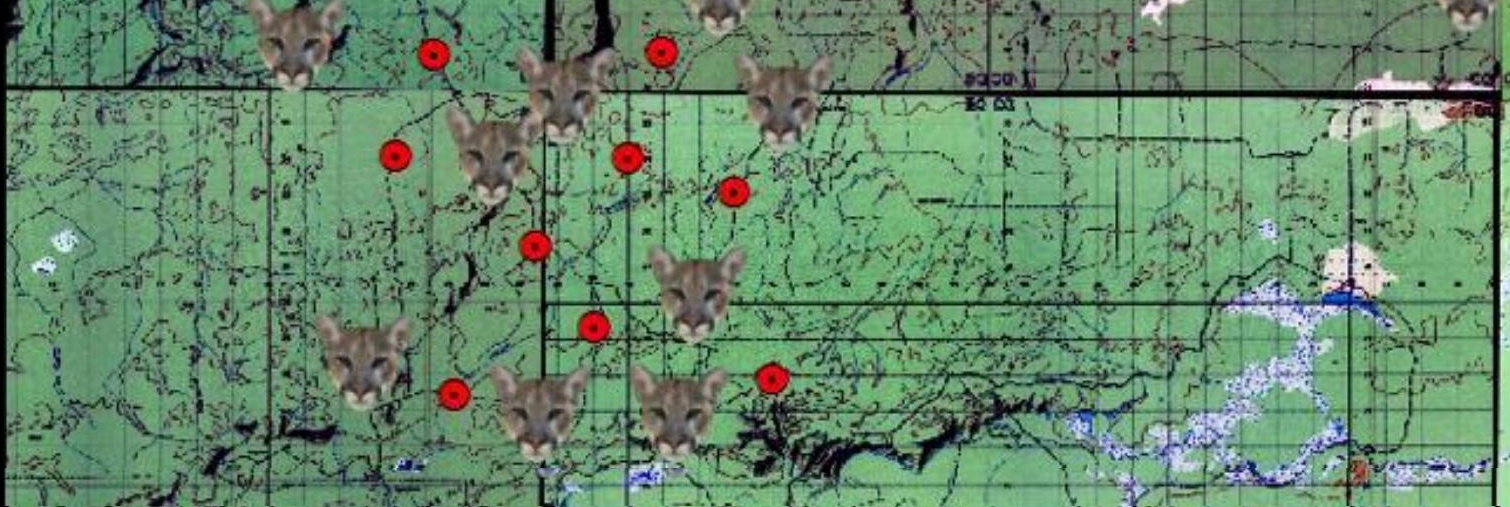
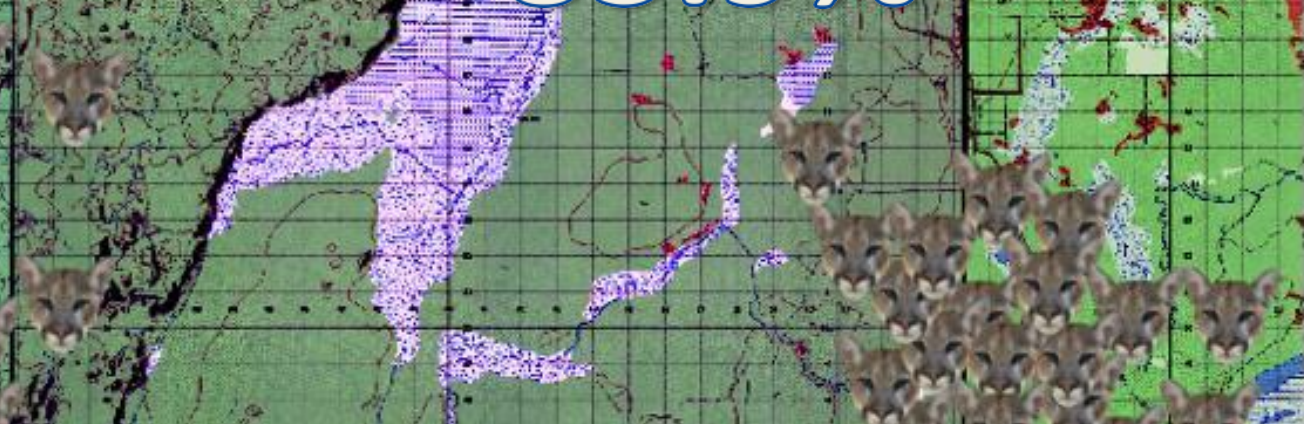


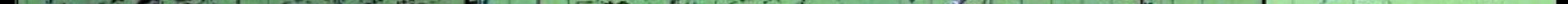




\section{Detection Modeling}

$\because$ Elusive wild cats are hard to study

- Remote noninvasive trail cameras help collect data

$\because$ A image is considered a single 'capture' event

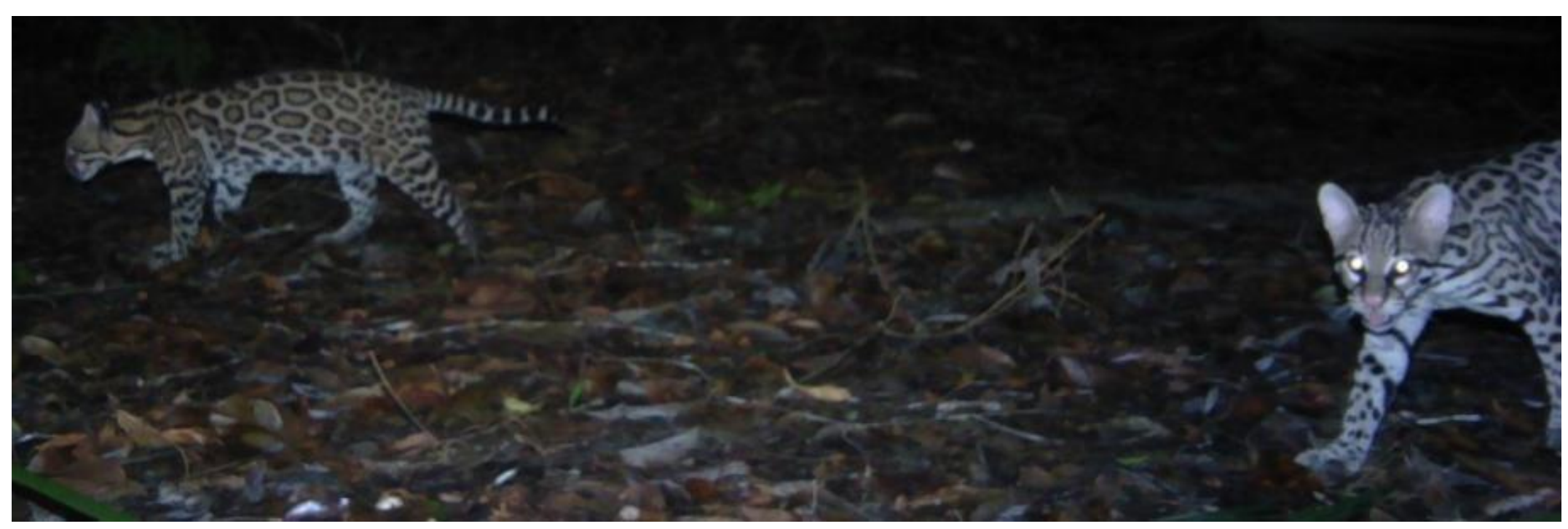




\section{Detection Modeling}

¿. Statistical model used accounts for not be able to 'capture' all animals at the camera station

* Accounts for animals that may not be detected

* Allows more accurate results and modeling

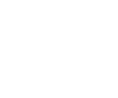




\section{Program PRESENCE}

$\because$ Statistical modeling software used for studying detection

* Data input on a week by week basis across 13 weeks

* Ran 16 models for all three interactions

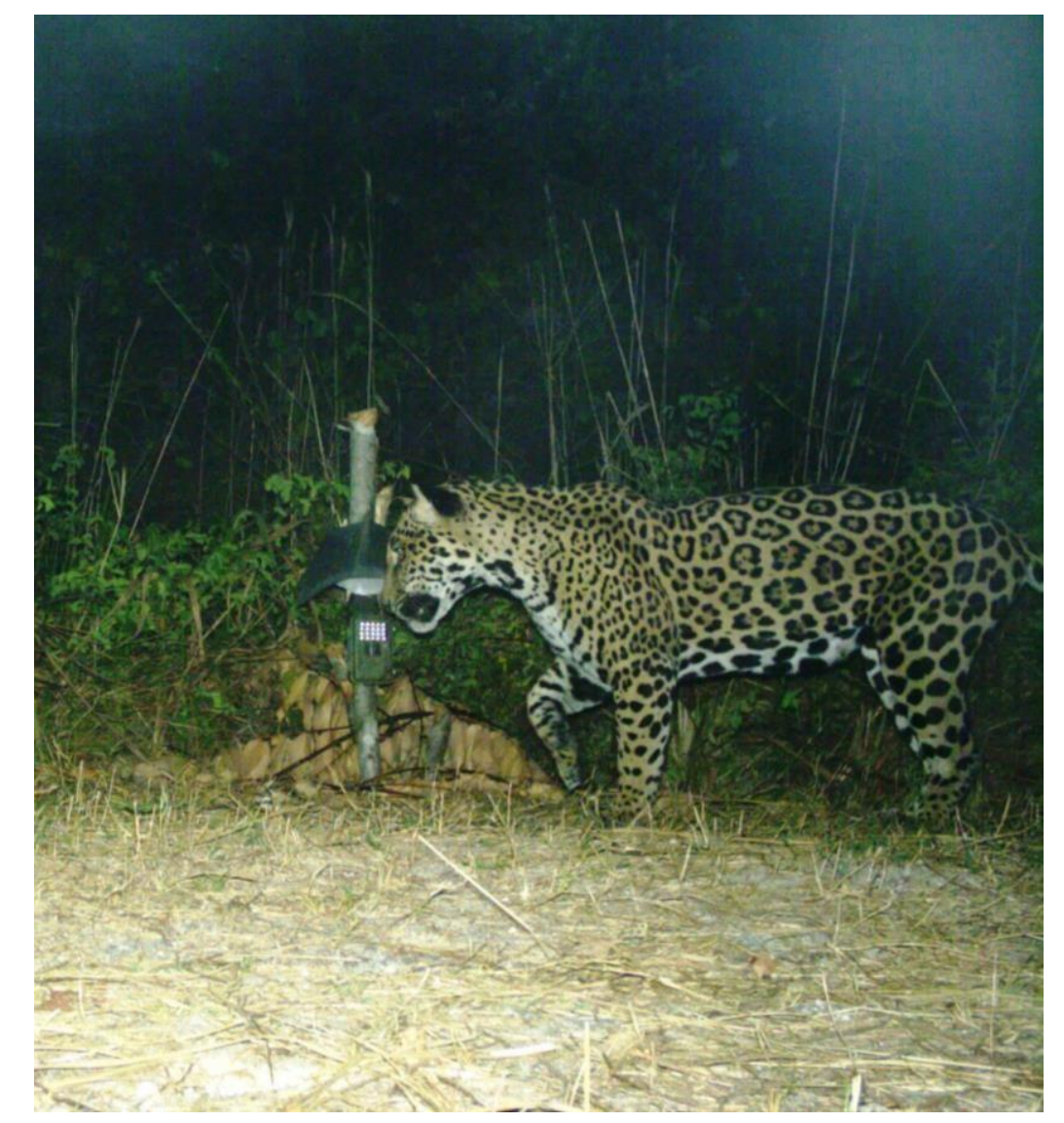




\section{Modifications to Detection Model}

\section{Normal Modeling}

* Studying interactions between two different species in modeling program PRESENCE

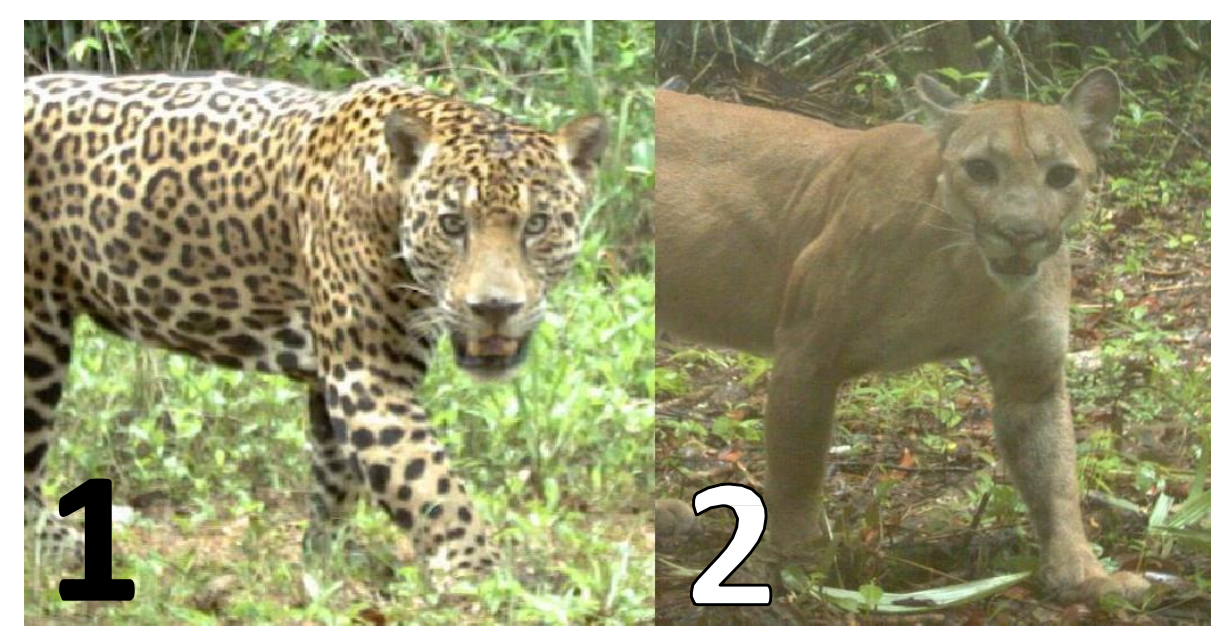

\section{Modified Modeling}

$\because$ Studying interactions within the same species

- Sexes used as two separate species in PRESENCE

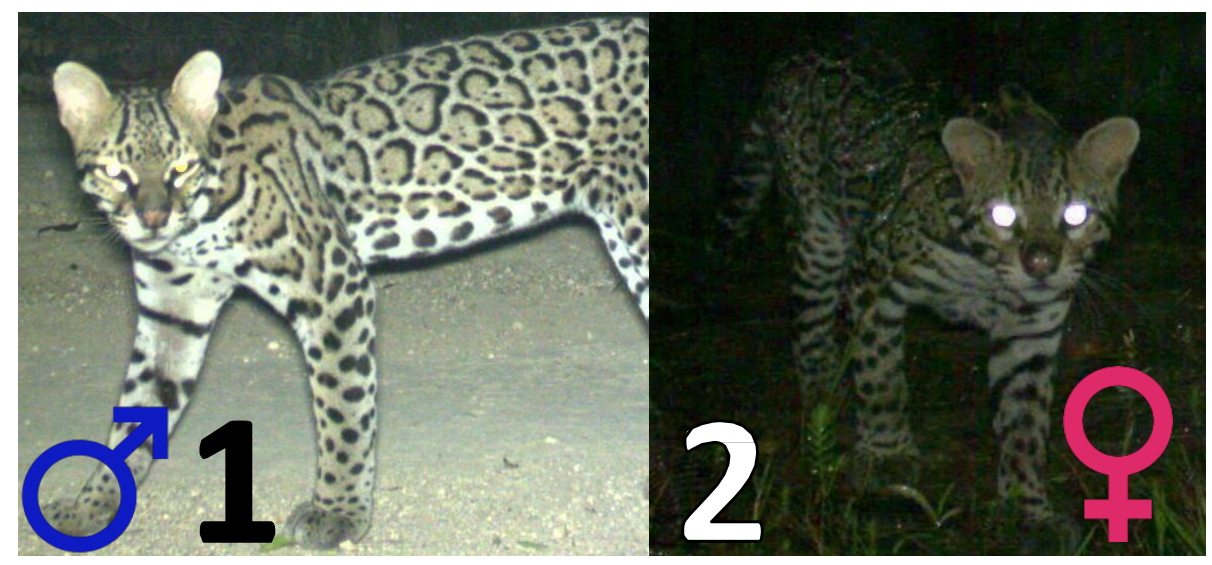




\section{Objective}

To determine how detection is influenced by sex within a species
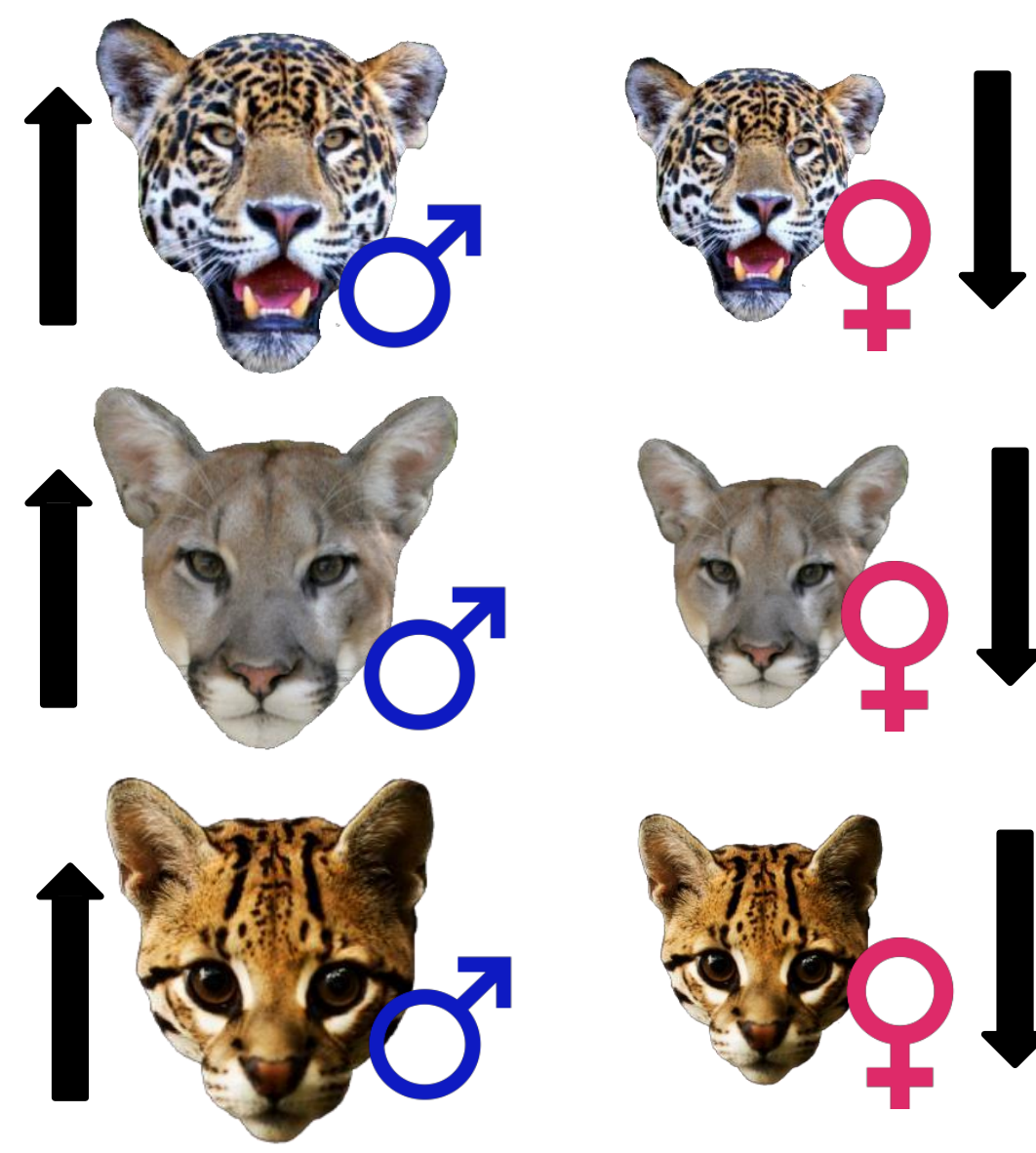

\section{Predictions:}

1.We expect the males across all species to have higher detection when females are present to find mates

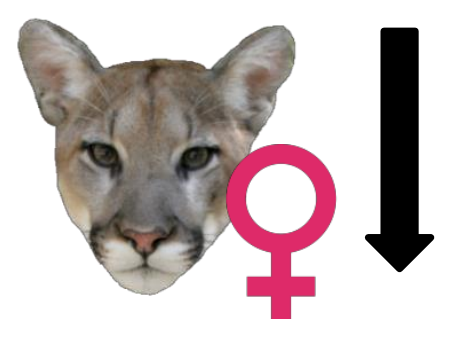

2.We expect females across all species to have lower detection

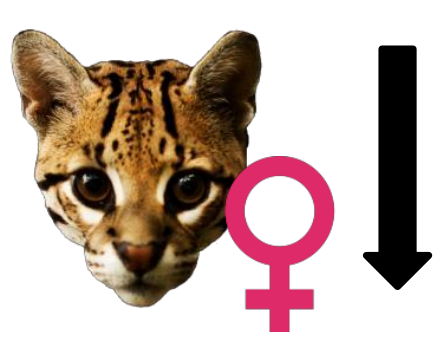
at stations where males are present because of infanticide 


\section{Data Set}

Average number of trap nights per station across all study sites $=64.2$ nights

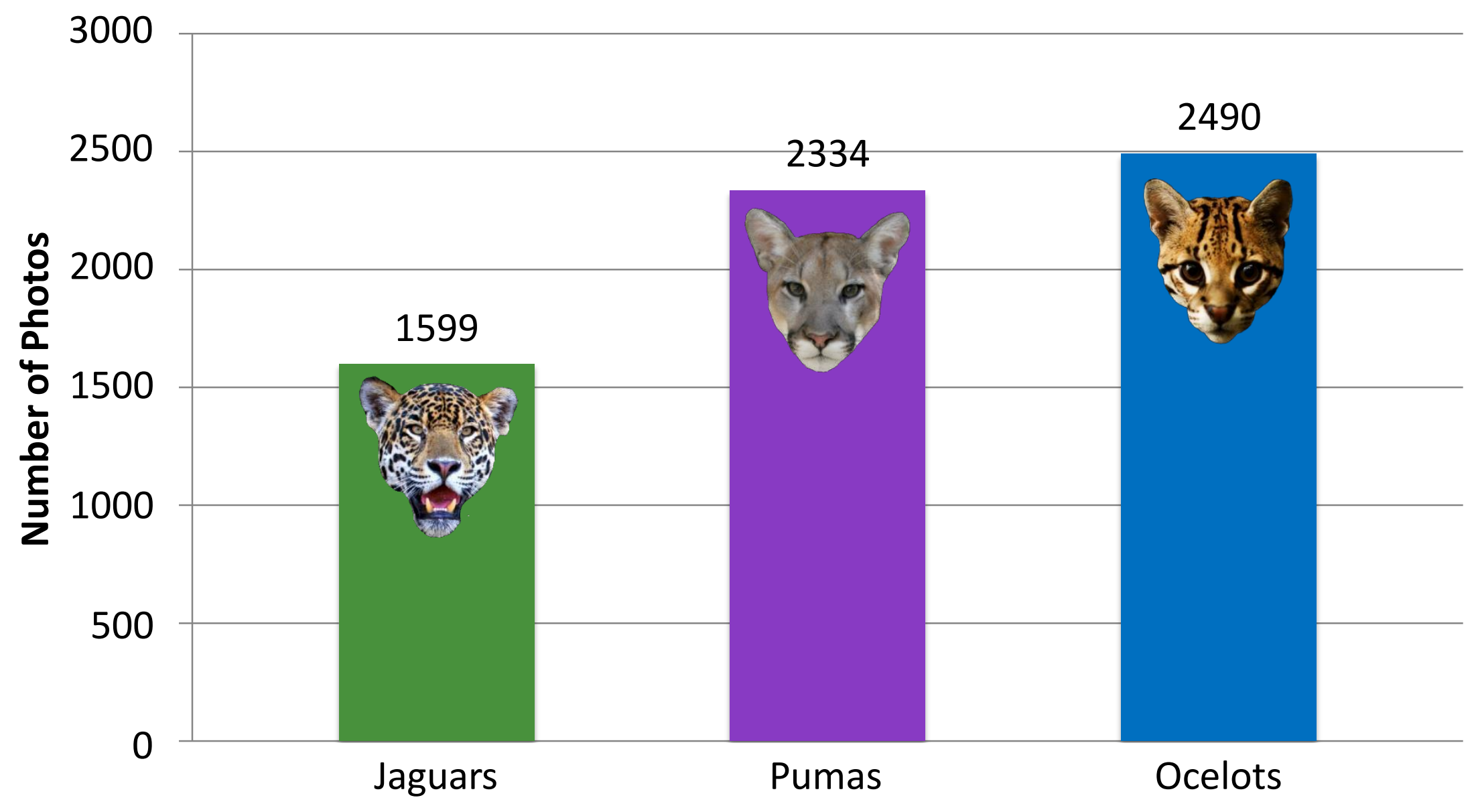




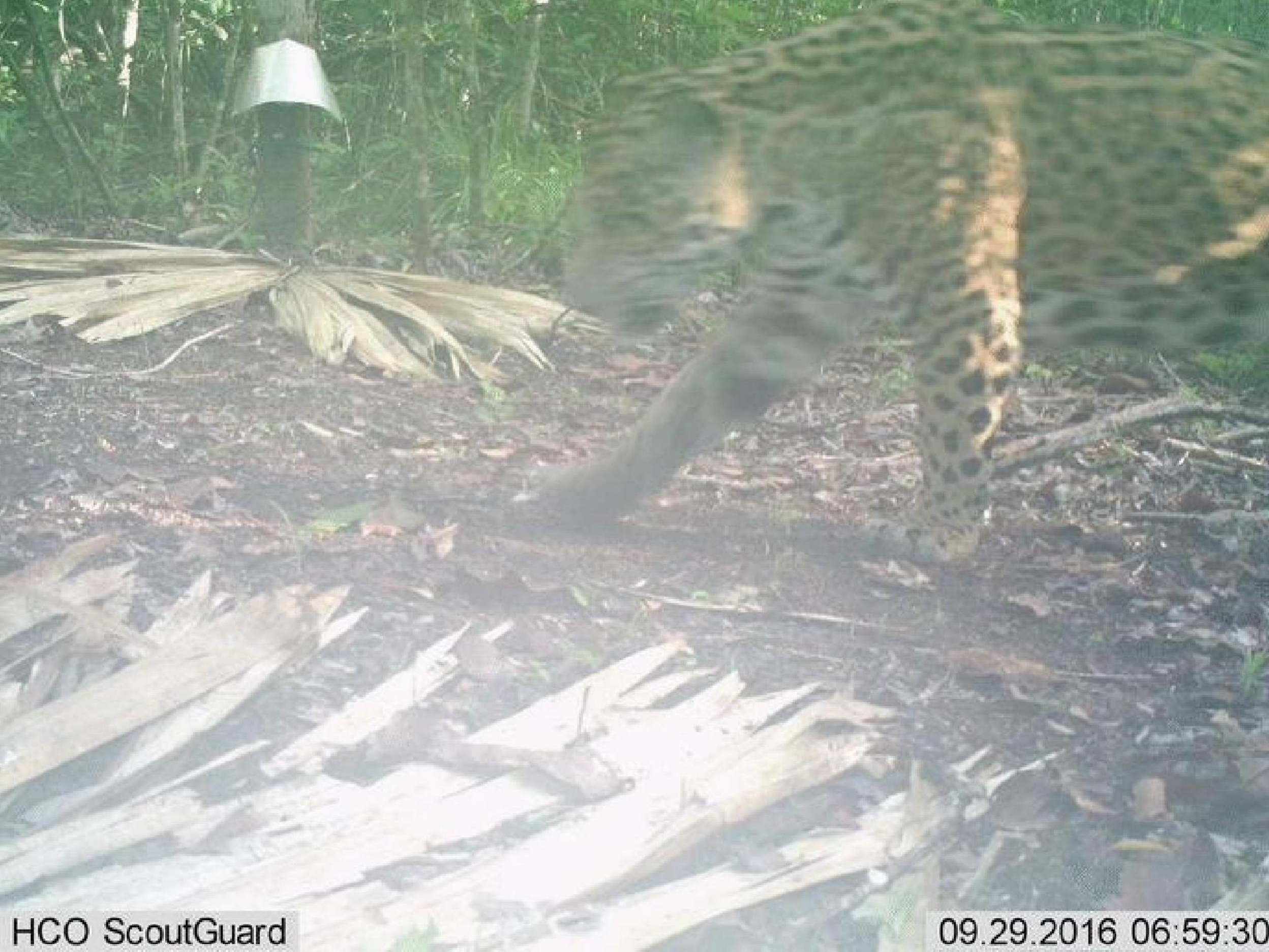




\section{Number Individuals of 'Captures' for All Four Study Sites}

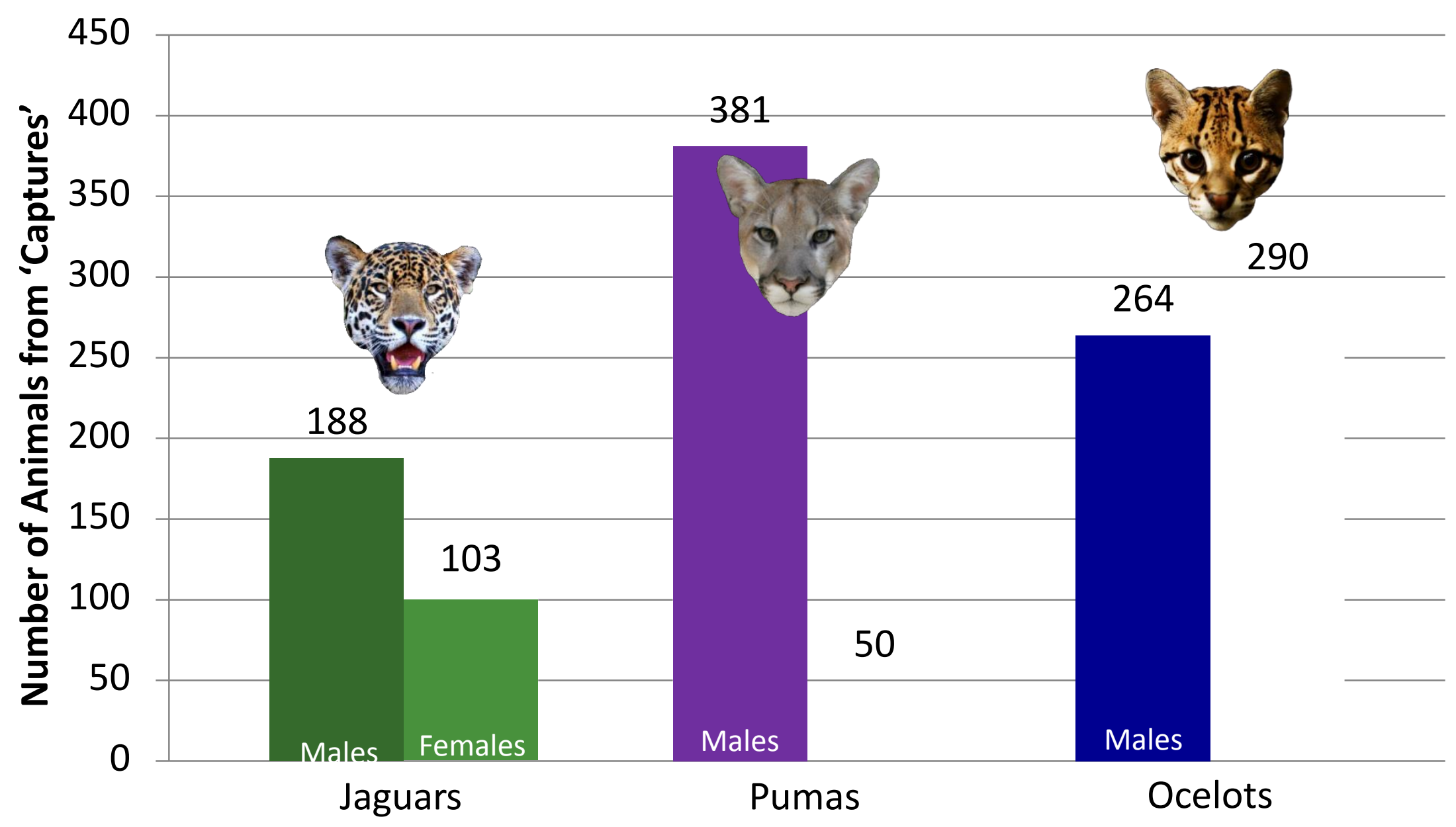




\section{Jaguar Male \& Female Detection}

Probability of Male Detection

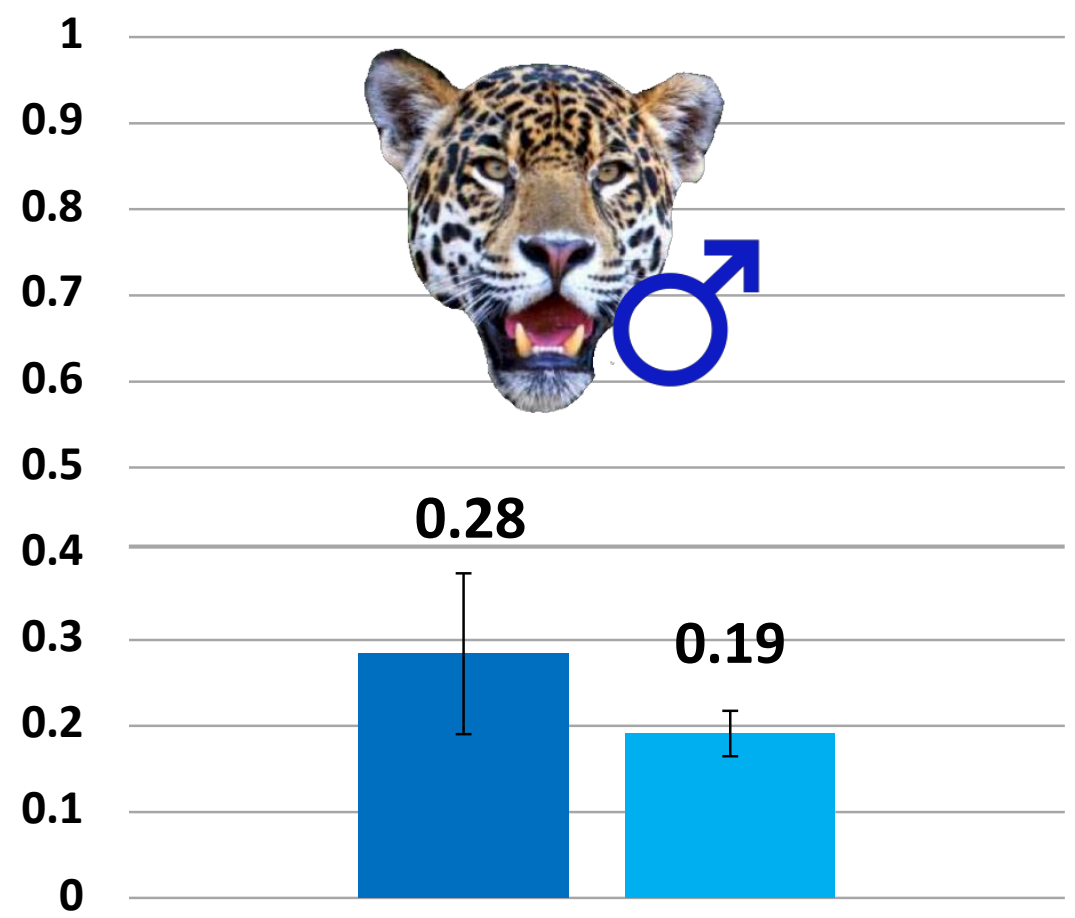

- Males when Females NOT Detected

Males when Females ARE Detected
Probability of Female Detection

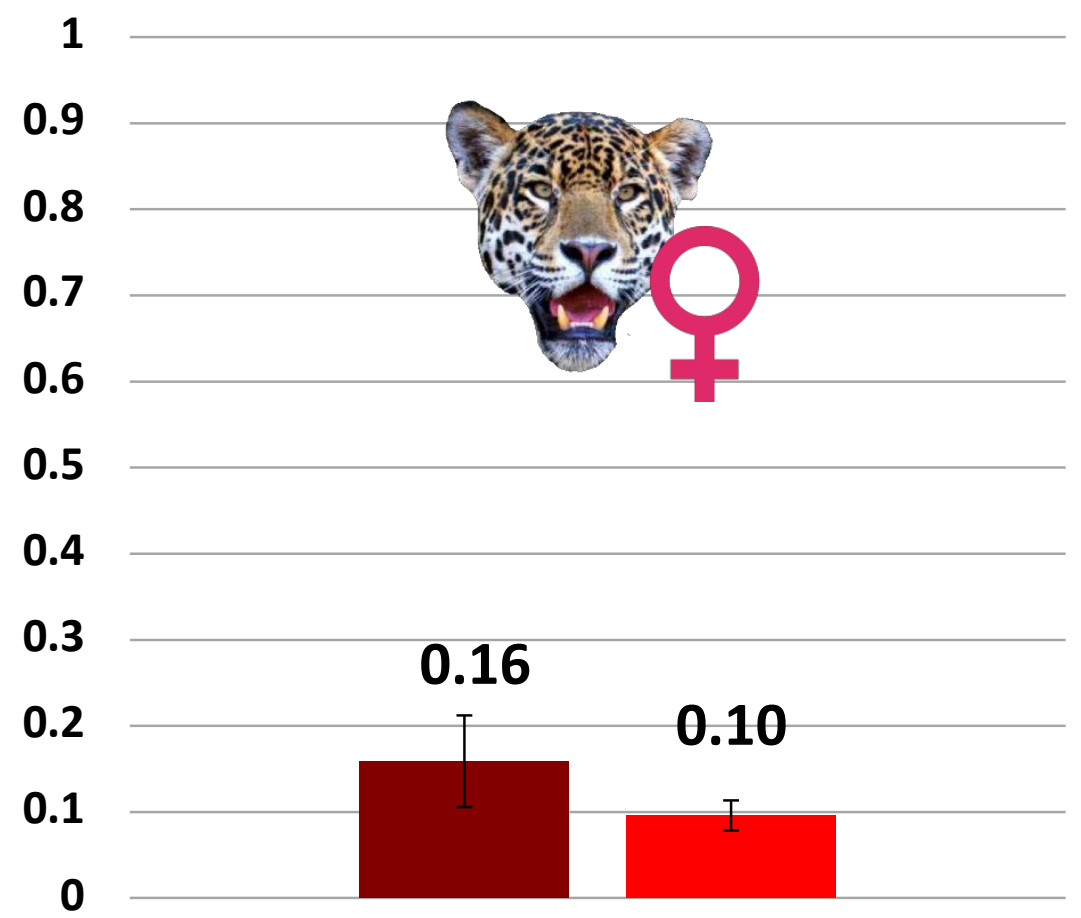

- Females when Males NOT Detected

- Females when Males ARE Detected 


\section{Puma Male \& Female Detection}

Probability of Male Detection

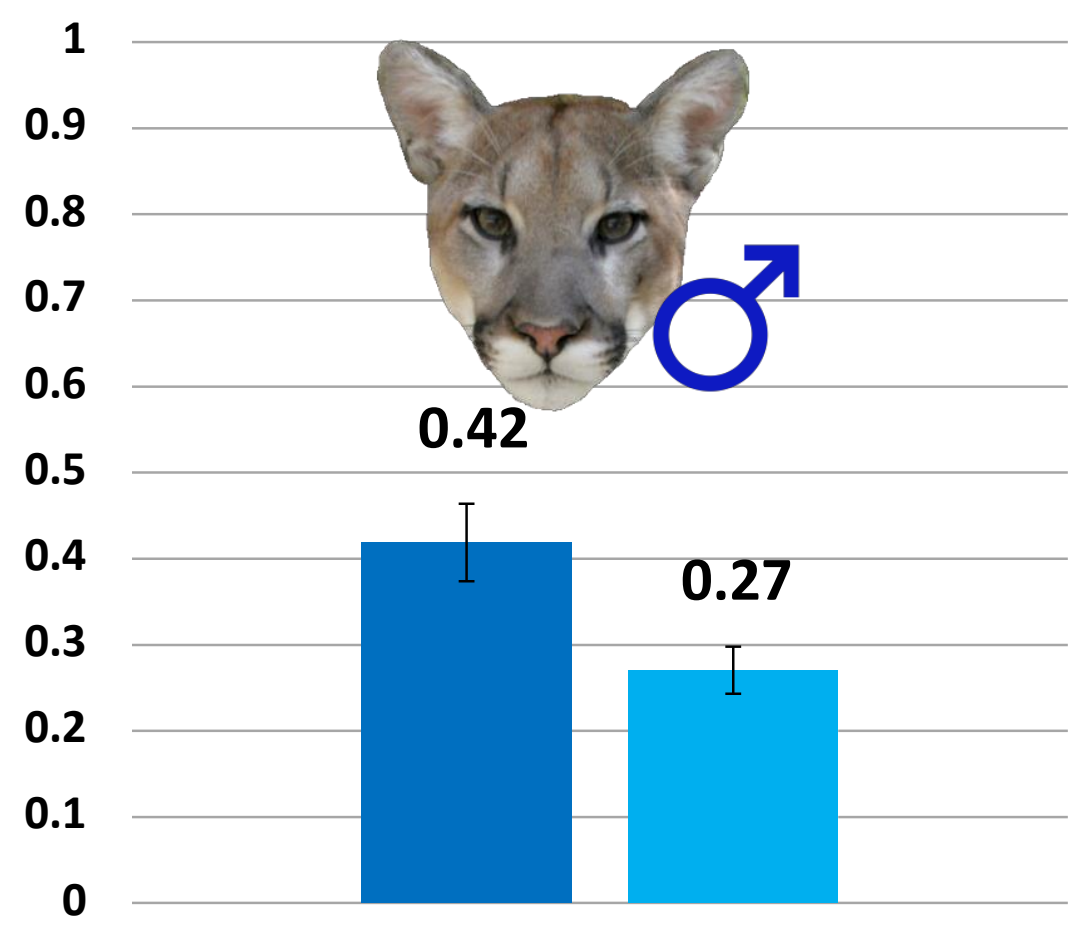

- Males when Females NOT Detected

Males when Females ARE Detected
Probability of Female Detection

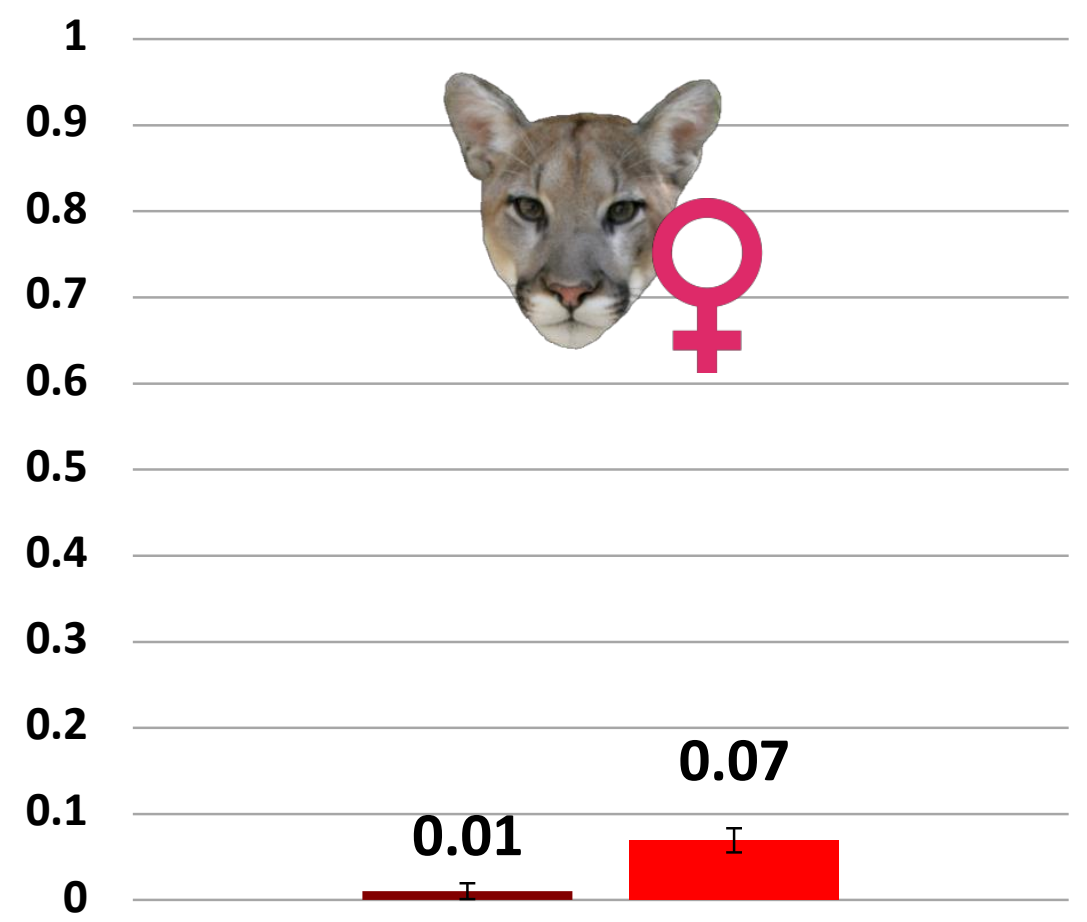

- Females when Males NOT Detected

- Females when Males ARE Detected 


\section{Ocelot Male \& Female Detection}

Probability of Male Detection

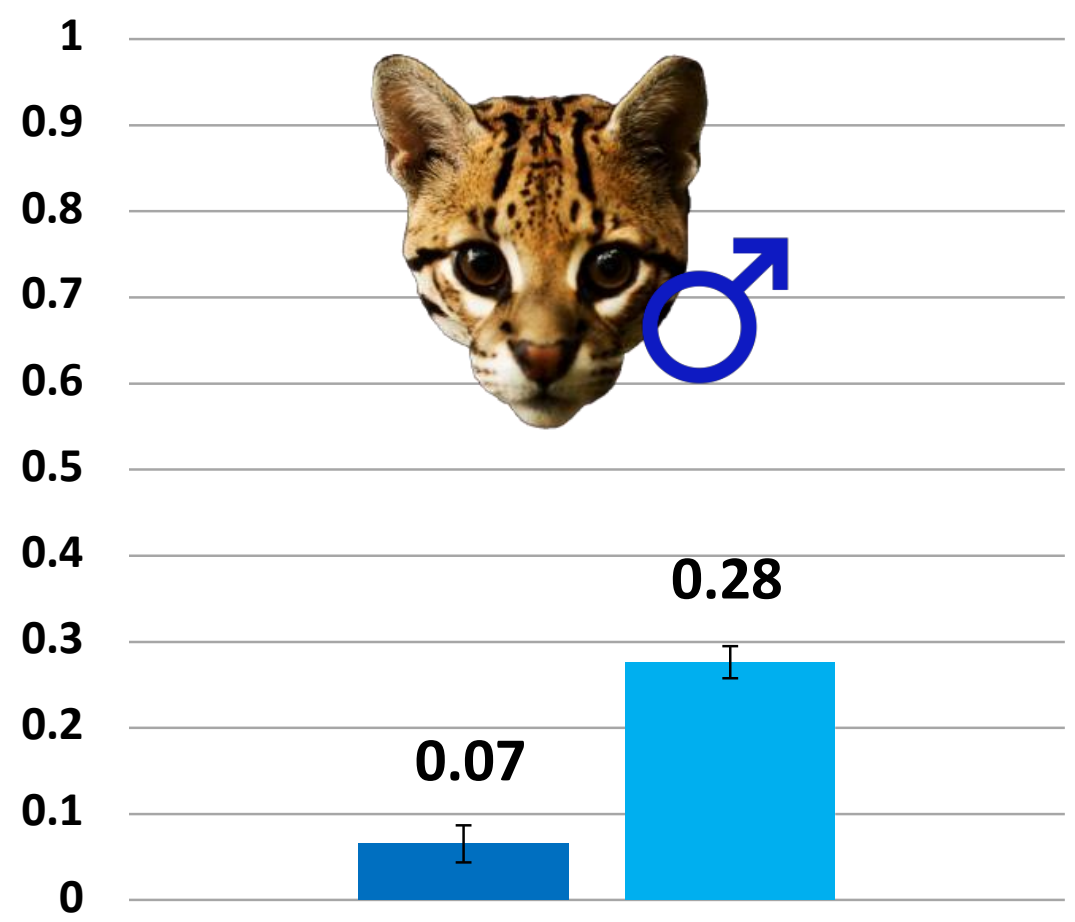

- Males when Females NOT Detected

- Males when Females ARE Detected
Probability of Female Detection

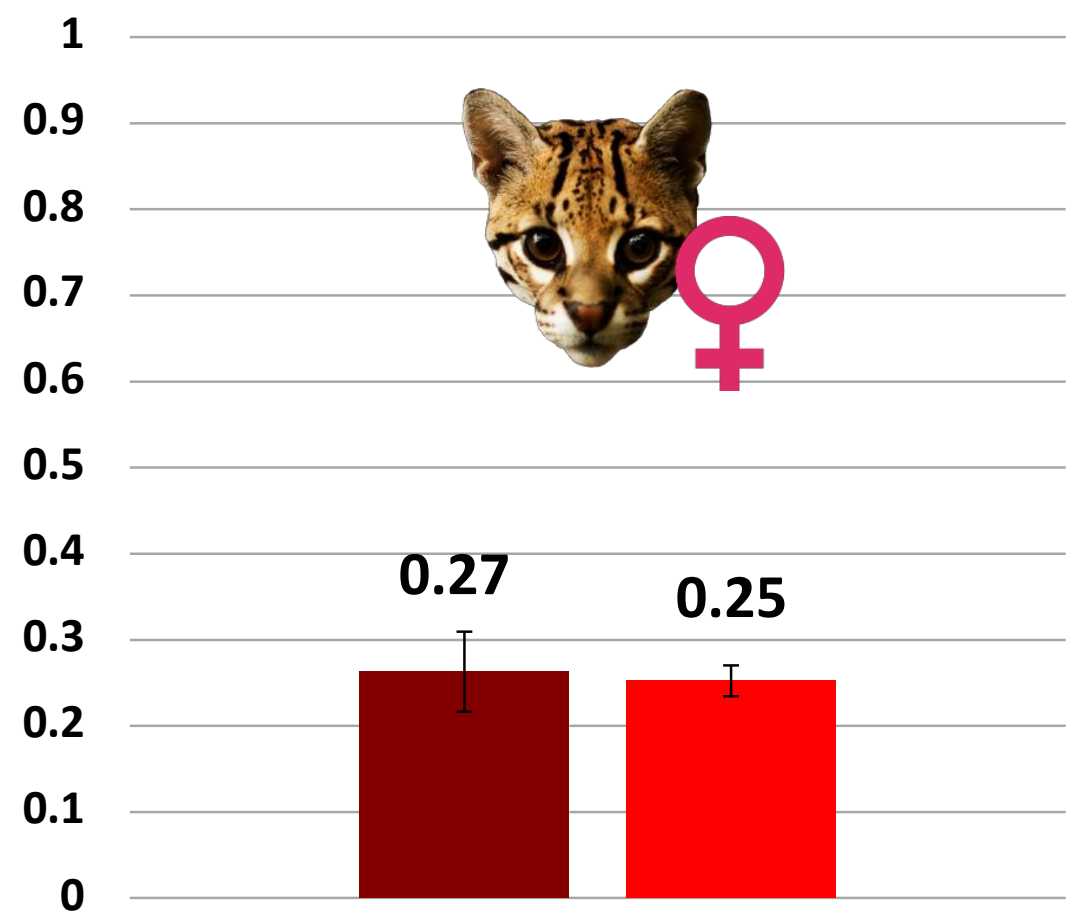

- Females when Males NOT Detected

Females when Males ARE Detected 


\section{Delta Interaction Values}

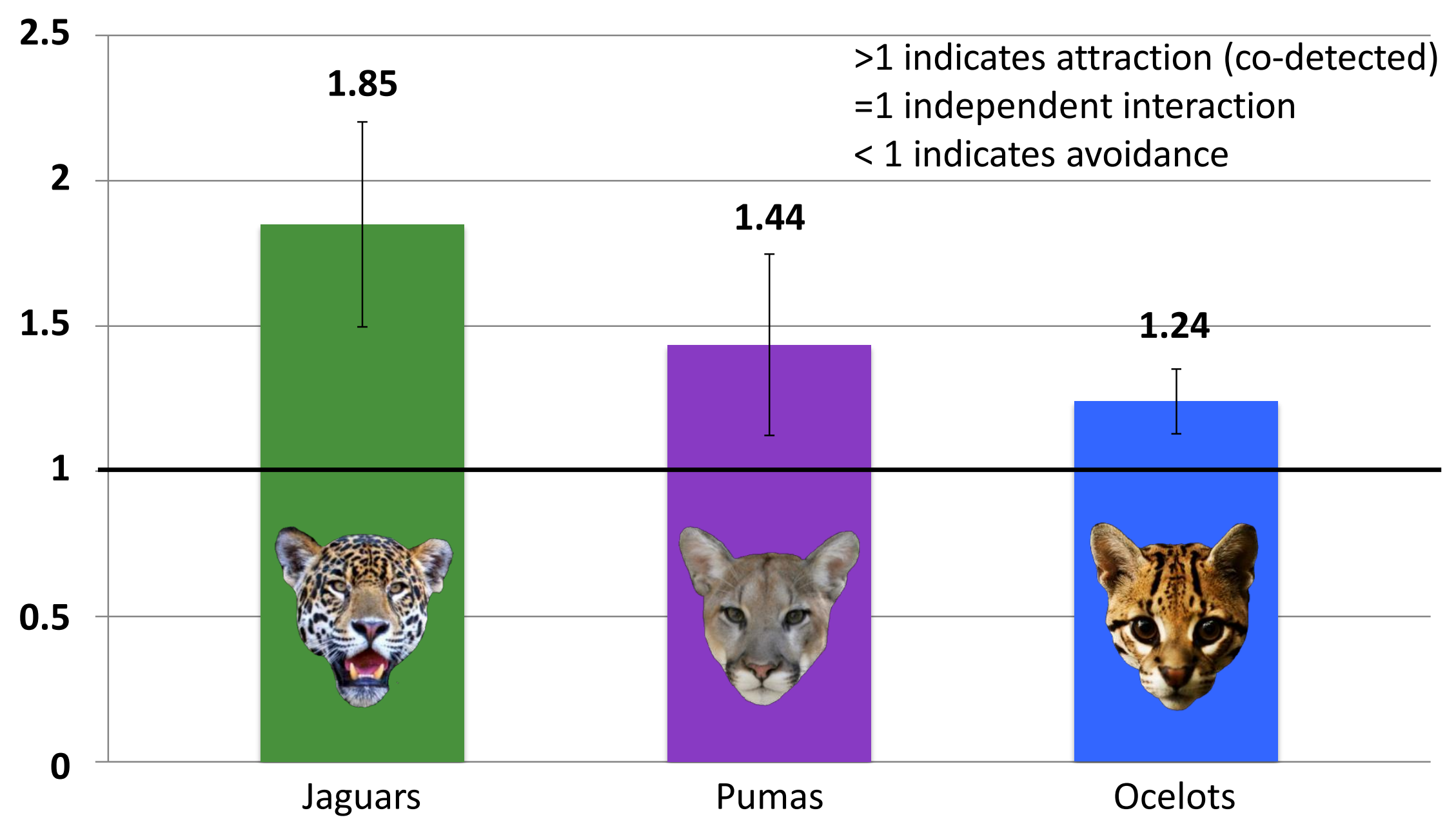




\section{Possible Causes of High Occupancy (Wide Distribution)}

: Plentiful resources

$\because$ Lack of competition

$\because$ Very dense habitat

$\because$ Effective conservation efforts for all species

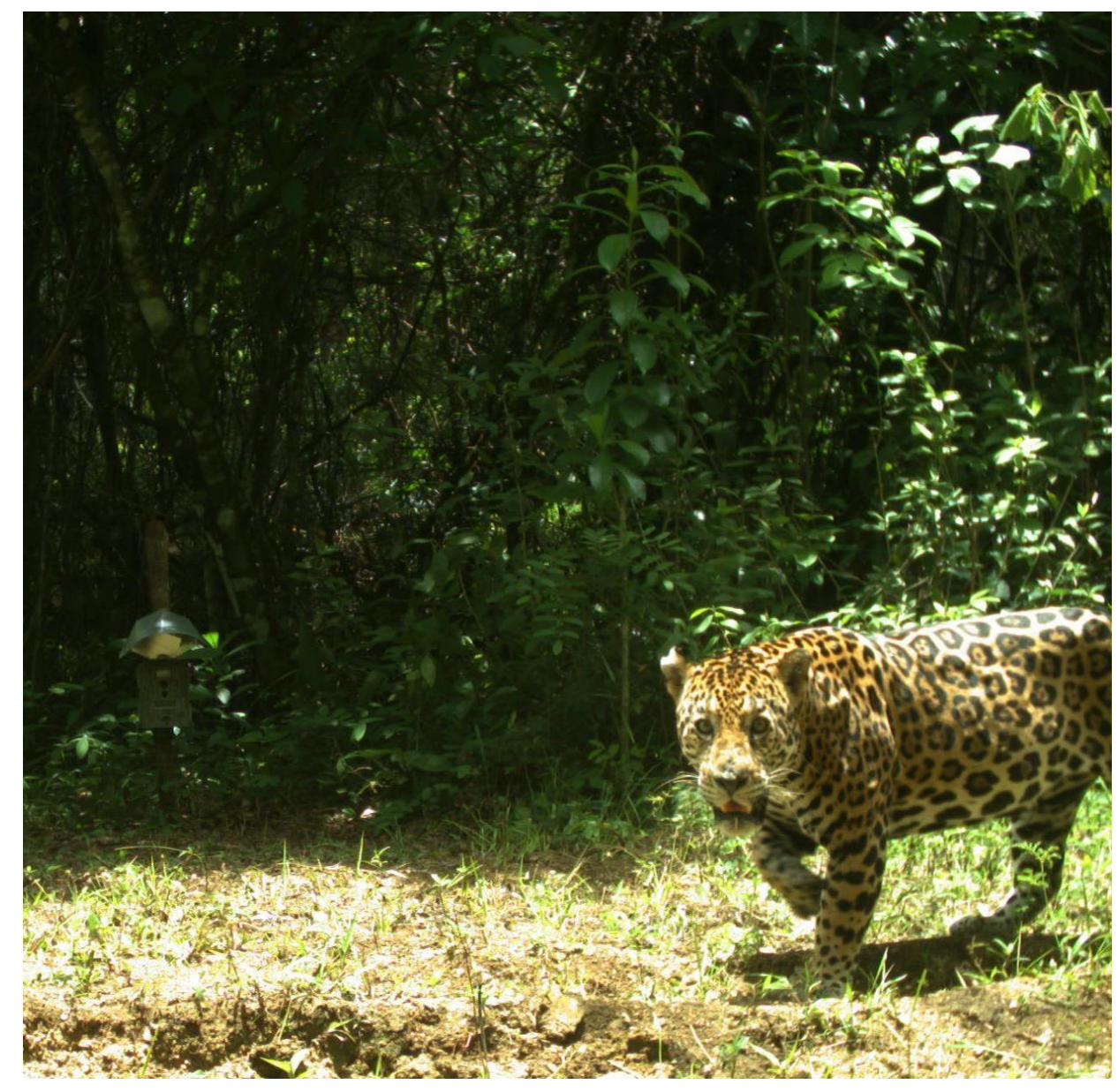




\section{Detection Summary}

* Jaguars - sexes had higher detection when other sex absent

$\because$ Pumas - opposite of what was expected

$\because$ Ocelots - expected results

$\because$ Delta values indicated co-detection

- No evidence of strong avoidance between sexes

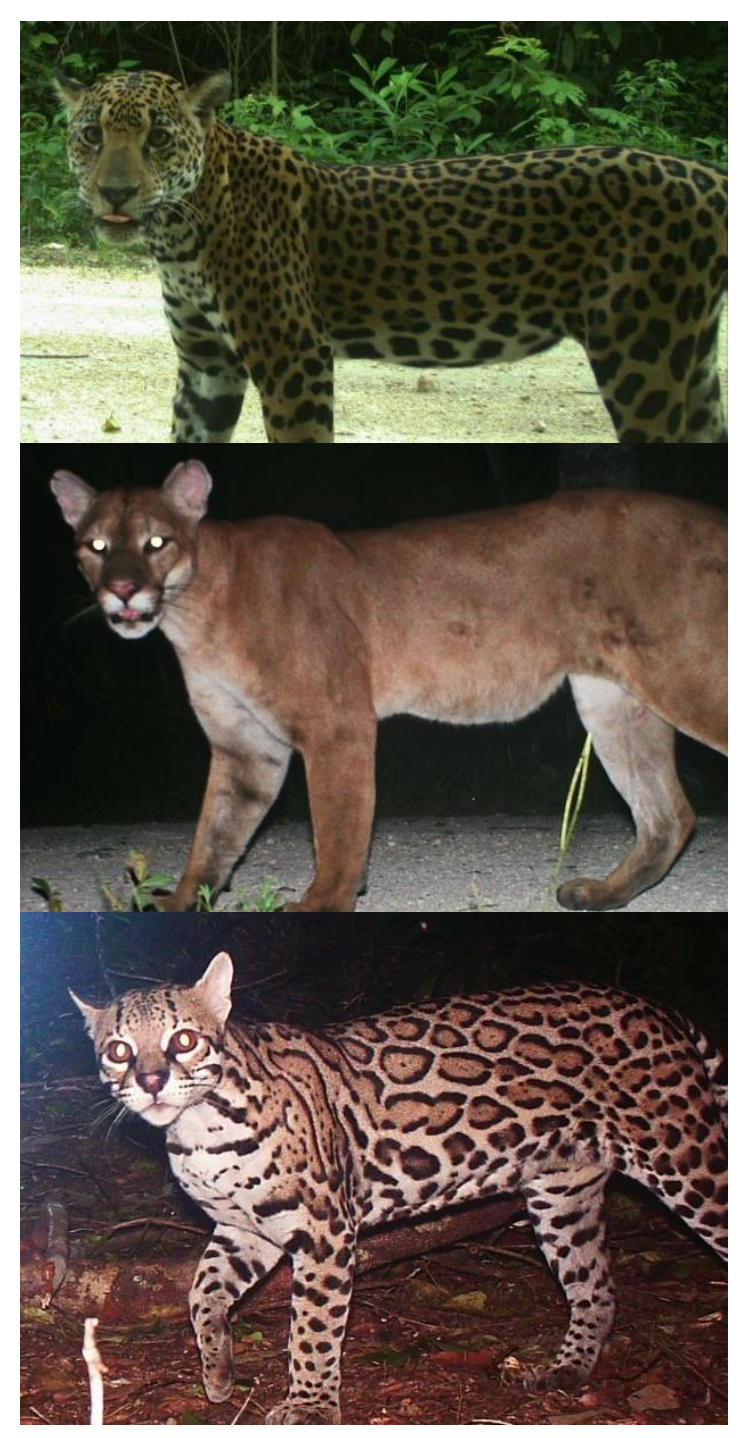




\section{Further Directions}

* Examine past years of data collected to

- Increase sample size

- Include other factors

- Human presence

- Prey presence

* Analyze on a day by day basis instead of a week by week basis

- More fine scale analysis

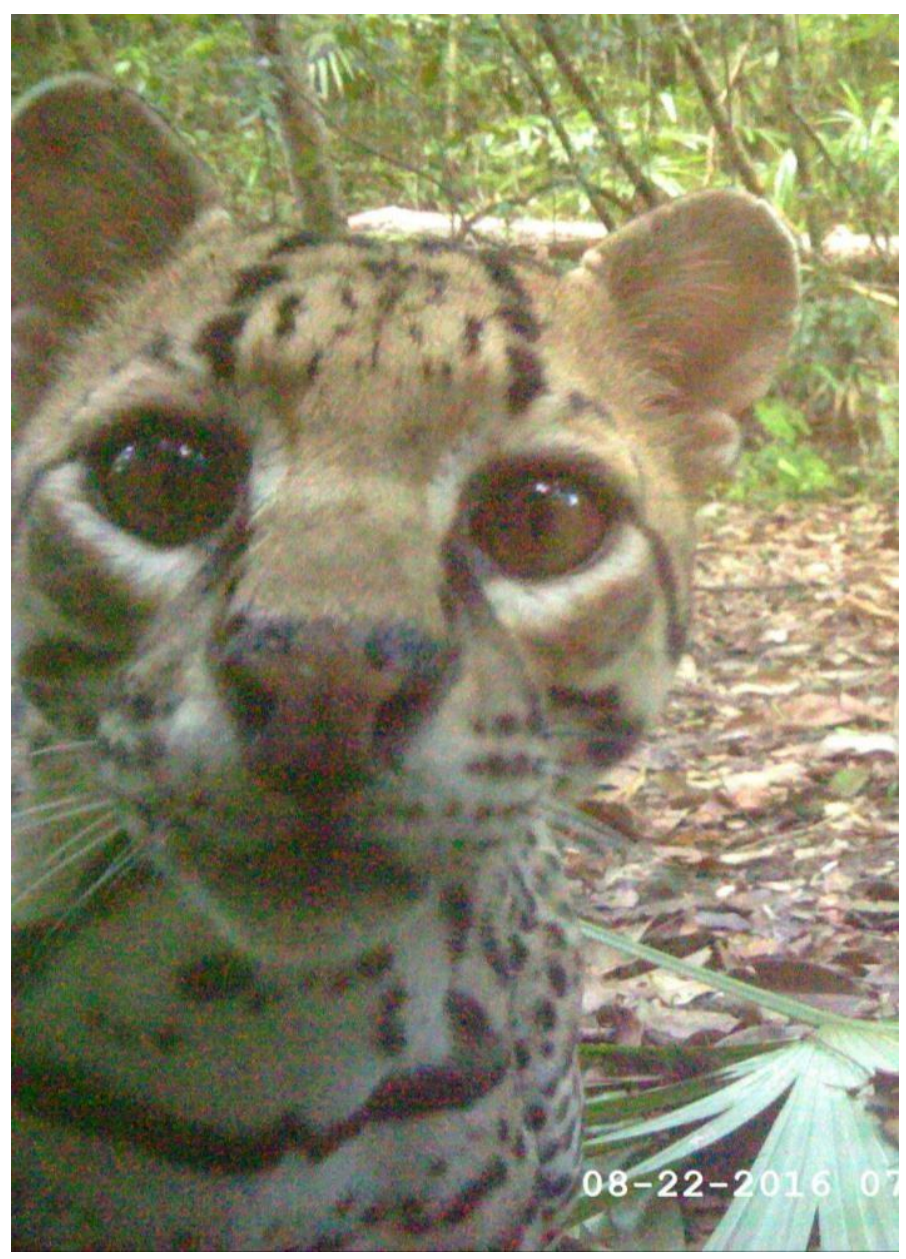




\section{Acknowledgement}

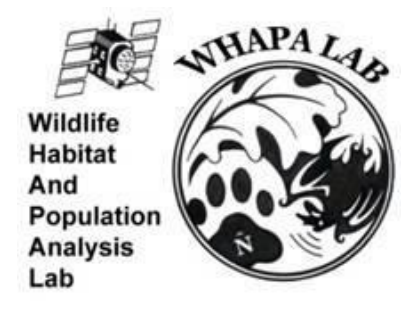

$\because \quad$ All the undergraduate students volunteering in Dr. Kelly's lab doing data entry and in the field collecting the raw photo data, this work would not be possible without their hard work

* Programme for Belize for their assistance \& permission to work on their land

$\approx$ Gallon Jug Estate for their assistance \& permission to work on their land

$\approx$ Yalbac Ranch and Cattle Corporation Limited (YRCC) for their assistance and permission to work on their land

\& Virginia Tech's Department of Fish \& Wildlife Conservation (FIW) \& Virginia Tech's Department of Animal \& Poultry Science (APSC)

* Virginia Tech's College of Natural Resources (CNRE) \& Virginia Tech's College of Agriculture \& Life Sciences (CALS)

* University of Belize for connecting interns with this project

Forest Department of Belize for permission to conduct this work
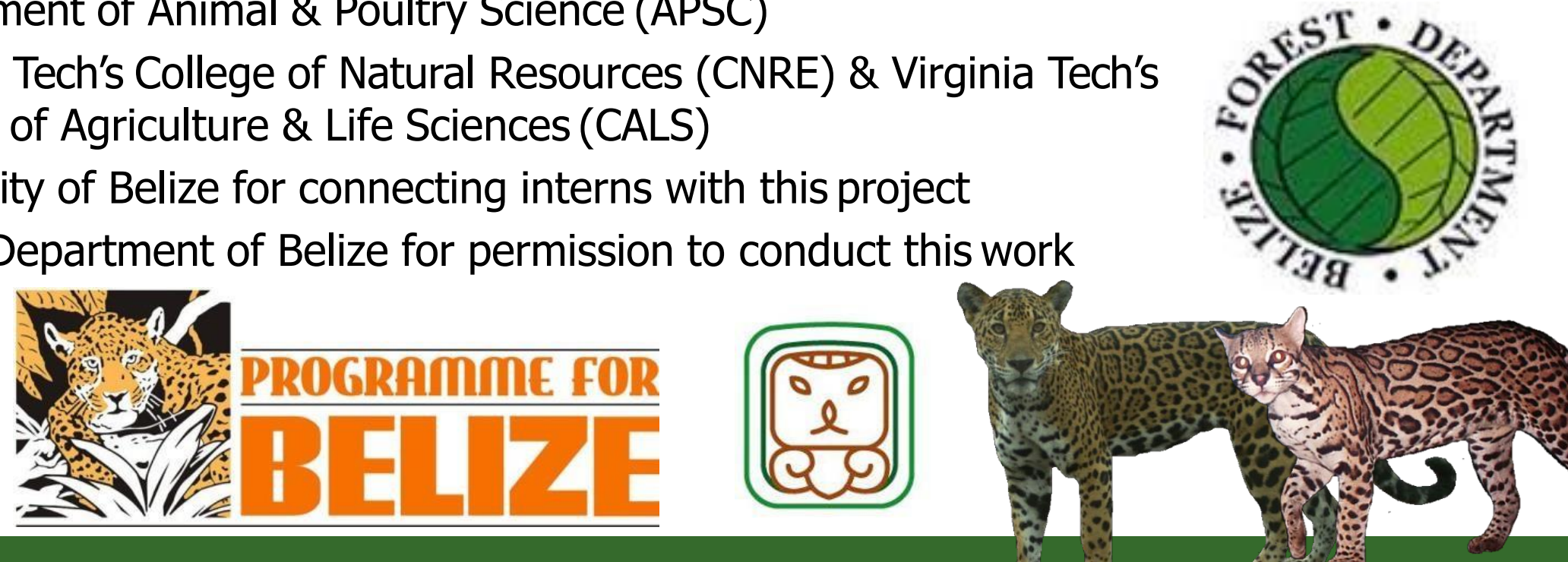


\section{Questions?}

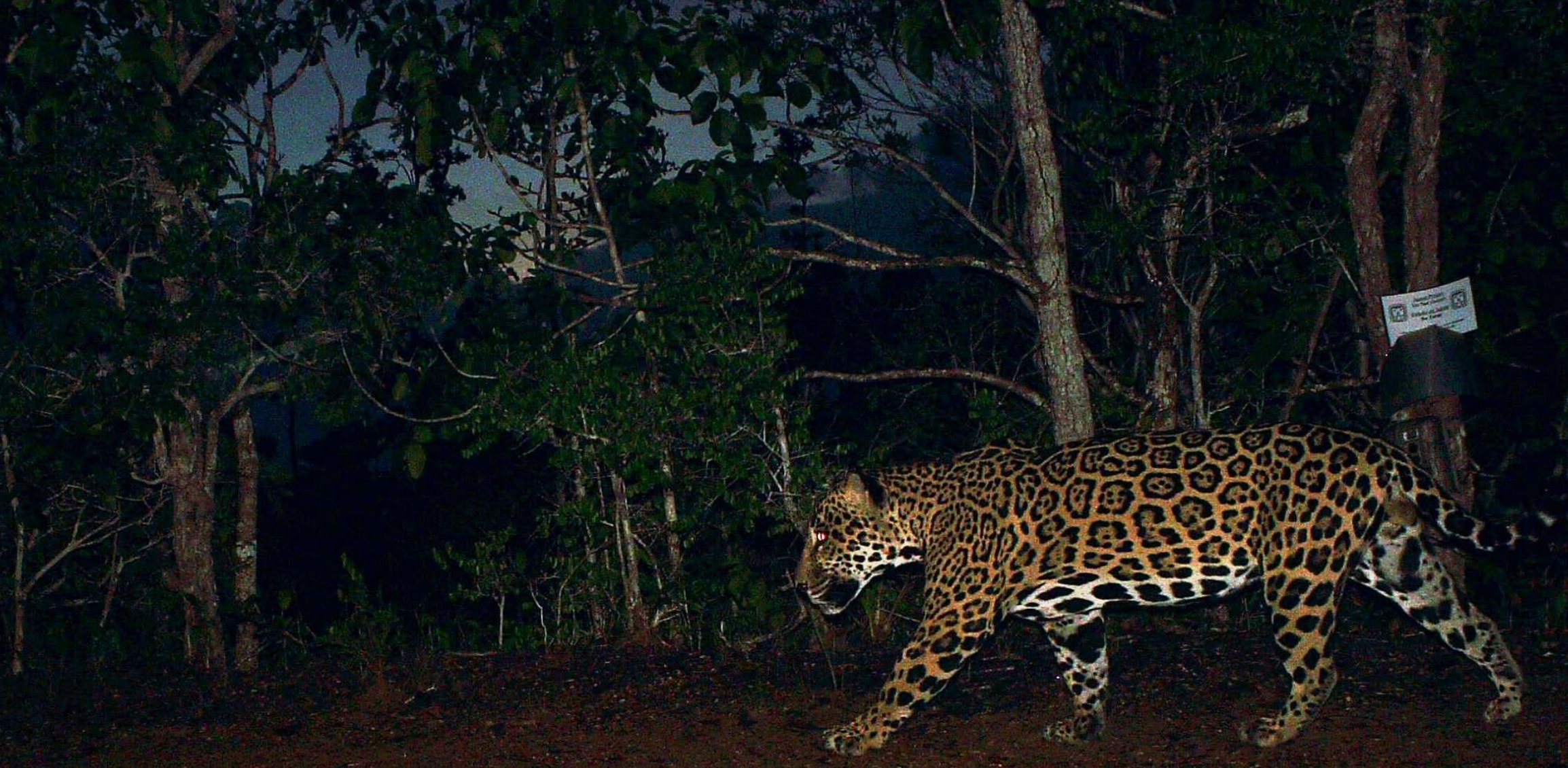

\section{Brogan Holcombe-brogy23@vt.edu}

See NCUR 2018 Proceedings for more info on this research 


\section{References}

* Ayala, F. J. 1969. Experimental invalidation of the principle of competitive exclusion. Nature224 : 1076-1079, [Accessed 4 Feb. 2018].

* Donadio, and Buskirk (2006). Diet, Morphology, and Interspecific Killing in Carnivora. The American Naturalist 167, 524.

* Hines, J. E., and D. I. MacKenzie. 2018. PRESENCE User Manual. USGS Patuxent Wildlife Research Center web page. < https://www.mbr-pwrc.usgs.gov/software/presence.html>. Accessed 28 April 2018.

* MacKenzie DI, Nichols JD, Lachman GB, Droege S, Royle JA, et al. 2002. Estimating site occupancy rates when detection probabilities are less than one. Ecology 83: 2248-2255.

* MacKenzie DI, Nichols JD, Hines JE, Knutson MG, Franklin AB. 2003. Estimating site occupancy, colonization, and local extinction when a species is detected imperfectly. Ecology 84: 2200-2207.

* Mackenzie, D.I., J.D. Nichols, J.A. Royle, K.H. Pollock, L.L. Bailey, and J.E. Hines. 2006. Occupancy estimation and modeling: inferring patterns and dynamics of species occurrence. Academic Press, London, United Kingdom.

* Palomares, F., and Caro, T. (1999). Interspecific Killing among Mammalian Carnivores. The American Naturalist 153, 492-508.

* PRESENCE, Mbr-pwrc.usgs.gov. (2018). Cite a Website - Cite This For Me. [online] Available at: https://www.mbr-

pwrc.usgs.gov/software/doc/presence/PRESENCE_examples_and_exercises.pdf [Accessed 4 Feb. 2018].

* Vojta, C. (2005). Old Dog, New Tricks: Innovations with Presence-Absence Information. Journal of Wildlife Management 69, 845-848, [Accessed 4 Feb. 2018].

* Wright, S., M. Gompper, and B. DeLeon. 1994. Are Large Predators Keystone Species in Neotropical Forests? The Evidence from Barro Colorado Island. Oikos 71:279. 